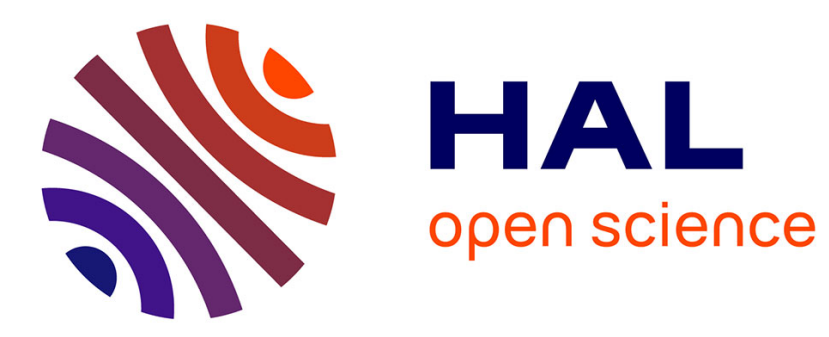

\title{
New insights on water storage dynamics in a mountainous catchment from superconducting gravimetry
}

Q Chaffaut, J Hinderer, F Masson, D Viville, S Pasquet, J P Boy, J D Bernard, N. Lesparre, M C Pierret

\section{To cite this version:}

Q Chaffaut, J Hinderer, F Masson, D Viville, S Pasquet, et al.. New insights on water storage dynamics in a mountainous catchment from superconducting gravimetry. Geophysical Journal International, 2021, 228, pp.432 - 446. 10.1093/gji/ggab328 . hal-03395252

\section{HAL Id: hal-03395252 \\ https://hal.science/hal-03395252}

Submitted on 22 Oct 2021

HAL is a multi-disciplinary open access archive for the deposit and dissemination of scientific research documents, whether they are published or not. The documents may come from teaching and research institutions in France or abroad, or from public or private research centers.
L'archive ouverte pluridisciplinaire HAL, est destinée au dépôt et à la diffusion de documents scientifiques de niveau recherche, publiés ou non, émanant des établissements d'enseignement et de recherche français ou étrangers, des laboratoires publics ou privés. 


\title{
New insights on water storage dynamics in a mountainous catchment from superconducting gravimetry
}

\author{
Q. Chaffaut ${ }^{\oplus},{ }^{1}$ J. Hinderer, ${ }^{1}$ F. Masson, ${ }^{1}$ D. Viville, ${ }^{1}$ S. Pasquet,${ }^{2}$ J.P. Boy ${ }^{\oplus},{ }^{1}$ \\ J.D. Bernard, ${ }^{1}$ N. Lesparre ${ }^{1}$ and M.C. Pierret ${ }^{1}$ \\ ${ }^{1}$ Institut Terre et Environnement de Strasbourg, Université de Strasbourg/EOST/ENGEES, CNRS UMR 7063, 5 rue Descartes, Strasbourg F-67084, France. \\ I-mal: chaffaut.quentin@gmail.com \\ 2 .......ut de physique du globe de Paris, Université de Paris, CNRS, F-75005 Paris, France
}

Accepted 2021 August 10. Received 2021 January 22

\begin{abstract}
SUMMAR Y
Assessing the spatial and temporal heterogeneity in subsurface water storage has strong societal and environmental implications, as it is key to assess the water availability for the ecosystem and society. This challenge is especially significant in mountainous areas, where the local population totally depends on springwater as a freshwater resource, while water storage dynamics is complex to evaluate because it exhibits spatiotemporal heterogeneities on all scales as a result of the topography. In this study, we compare the water balance of a headwater granitic catchment (CWB) with water storage changes assessed from in situ continuous gravity monitoring using an iGrav superconducting gravimeter $\left(\mathrm{SG}_{\mathrm{WSC}}\right)$ located at the summit of the catchment. We show that $\mathrm{SG}_{\mathrm{WSC}}$ and $\mathrm{CWB}$ exhibit a similar annual cycle, although they deviate in the months following winter peak flow events. We investigate the reasons for these discrepancies using a tank model adjusted to the SG signal. This shows that during these events, the effective discharge in the SG footprint area is much lower than the catchment streamflow. We attribute this difference in the drainage term to a lower contribution of the upper part of the catchment to the generation of peak flow, compared to the lower part.
\end{abstract}

Key words: Hydrogeophysics; Hydrology; Loading of the Earth; Time variable gravity.

\section{INTRODUCTION}

Assessing the spatial and temporal heterogeneity in subsurface water storage is one of the big challenges identified by the growing critical zone (CZ) community (e.g. Brooks et al. 2015; Parsekian et al. 2015). This has strong societal and environmental implications, as it allows, for example, to understand the links between the water storage dynamic and the vegetation (Rempe 2016), and hence to better assess the effect of water stress on the vegetation, which should help guiding vegetation management (Grant et al. 2013). Understanding the water storage dynamics is also a key to identify streamflow generation processes (Ladouche et al. 2001; Creutzfeldt et al. 2013). Among the wide spectrum of hydro-systems, mountainous areas provide a good illustration of the complexity and relevancy of such challenge: In mountain, springwater is the only drinking water resource available, which is indispensable for local agriculture, industrial water supply and municipal water supply (Viviroli et al. 2011) but also for the adjacent lowlands (Viviroli et al. 2007). However, the water storage dynamics is difficult to assess because the topography gives rise to major lateral redistribution of water and energy, and considerable heterogeneity on all scales, which limits the areal representativeness of any point measurement to assess either fluxes or parameters (Ambroise 1995).
The development of hydro-geophysical methods to probe the subsurface water content allows to cope with this measurement challenge from the field scale to the catchment scale (Bogena et al. 2015). Among them, terrestrial gravimetry is particularly well suited because it can measure water storage changes at an intermediate scale (some tens of thousands square metres) once appropriate corrections have been applied onto the gravity signal (mostly tidal and atmospheric corrections). Gravimetry is also an integrative measurement which is sensitive to WSC occurring in every storage compartment of the hydro-system: vadose zone (Fores et al. 2018), snowpack (Flury et al. 2007) and aquifer (Pfeffer et al. 2013). Creutzfeldt et al. (2014) showed that independent storage measurement inferred from in situ gravimetry, in combination with streamflow measurements on the neighbouring catchments provides insights into the large-scale structure of mountainous hydrological systems than can help to characterize hydrological processes throughout a basin. In this study, we argue that the combination of WSC estimated from a superconducting gravimeter $\left(\mathrm{SG}_{\mathrm{WSC}}\right)$ installed at the summit of the Strengbach headwater catchment located in the Vosges mountain in France, with the catchment water balance (CWB) yields valuable information about the streamflow generation processes occurring in this mountain hydro-system. 
The gravity signal resulting from hydrology is commonly divided into a kilometric scale local hydrological contribution and a nonlocal continental scale hydrological contribution (Llubes et al. 2004; Creutzfeldt et al. 2008; Longuevergne et al. 2009). A wide diversity of geomorphological contexts with temperate climate has been explored with in situ time-variable gravimetry: karstic environments (Jacob et al. 2008; Deville et al. 2013; Fores et al. 2017; Fores et al. 2019; Watlet et al. 2020), hilly environments located on detritic basins (Meurers et al. 2007; Longuevergne et al. 2009; Mikolaj et al. 2015), mid-altitude mountainous environments with intact bedrock covered by a saprolite layer (Kroner \& Jahr 2006; Hasan et al. 2008; Creutzfeldt et al. 2010b; Naujoks et al. 2010; Masson et al. 2012; Creutzfeldt et al. 2014; Güntner et al. 2017; Chaffaut et al. 2020), or alpine environments (Arnoux et al. 2020; Voigt et al. 2021). Tropical climate environments with strong monsoonal signal such as west Africa or Taiwan have also been investigated with time-variable in situ gravimetry (Christiansen et al. 2011; Pfeffer et al. 2011; Mouyen et al. 2012; Hector et al. 2014; Hector et al. 2018; Hinderer et al. 2020).

Several deterministic and empirical methods have been developed to link the measured gravity signal resulting from the local hydrology to the local hydrological processes. In a first approach, the modelled hydro-gravimetric signal is computed from local hydrometeorological measurements assuming a simple spatial distribution for WSC, for example, the Bouguer slab hypothesis (Jacob et al. 2008; Longuevergne et al. 2009). Another approach relies on the adjustment of conceptual hydrological models on the measured local hydrological gravity signal (e.g. Hasan et al. 2008; Deville et al. 2013; Fores et al. 2017; Güntner et al. 2017). In a third approach, the local hydrological gravity signal is used to calibrate physically based hydrological models (Creutzfeld et al. 2010; Christiansen et al. 2011; Fores et al. 2018; Hector et al. 2018).

Among the different types of gravimeters available, the superconducting gravimeters (SG) are particularly well suited to study hydrological processes which produce gravity variations whose timescales range from a few minutes (e.g. for a rain event, Delobbe et al. 2019, or for measuring the daily evapotranspiration cycle, Van Camp et al. 2016) to several years (e.g. for long-term water storage recovery after a significant drought, Creutzfeld et al. 2012). An SG is a relative gravimeter whose output voltage is directly proportional to gravity (see Hinderer et al. 2015 for a review). SG is currently the most sensitive relative gravimeter available and exhibits very good long-term stability of the scale factor (Calvo et al. 2014) and drift (Warburton et al. 2010). For iGrav-type SG, noise level as small as $1 \mathrm{~nm} \mathrm{~s}^{-2}$ has been demonstrated for an integration time of $60 \mathrm{~s}$. Thanks to repeated absolute gravity (AG) measurements, drift has already been proven to be lower than $50 \mathrm{~nm} \mathrm{~s}^{-2} \mathrm{yr}^{-1}$ and linear for an iGrav SG (e.g. $45 \mathrm{~nm} \mathrm{~s}^{-2} \mathrm{yr}^{-1}$, Fores et al. 2017), although more studies are required to confirm the linearity of iGrav-type SG.

In this study, we rely on continuous gravity monitoring performed with an iGrav SG (Warburton et al. 2010) installed in 2017 June at the summit of the small Strengbach headwater catchment (Fig. 1). Here, the SG is intentionally located on the summit to increase the footprint and amplify the sensitivity to the local WSC. Strengbach CWB and $\mathrm{SG}_{\mathrm{WSC}}$ are two different integrals of WSC: CWB integrates WSC occurring in the Strengbach catchment, while $\mathrm{SG}_{\mathrm{WSC}}$ integrates WSC occurring in the upper part of the Strengbach catchment and the two neighbouring catchments. Daily to annual SG gravity variations related to local hydrology are characterized to address the following issue: what insights does the SG gravity signal bring onto the hydrological functioning of a mountain headwater catchment? We first describe the field context in Section 2.
In Section 3, the methodology used to extract the local hydrological contribution from the measured gravity signal is detailed, and we evaluate the effect of the WSC spatial distribution on the SG signal, which allows to provide upper and lower bounds for the so-called $\mathrm{SG}_{\mathrm{WSC}}$. In Section $4, \mathrm{SG}_{\mathrm{WSC}}$ is compared at the annual timescale with CWB on the one hand and global hydrological models MERRA2 (Modern-Era Retrospective analysis for Research and Applications, Version 2, Gelaro et al. 2017) and GLDAS2/Noah v.1 (Global Land Data Assimilation System version 2) (Rodell et al. 2004) on the other hand. Differences between $S_{W S C}$ and CWB are then investigated using a tank model adjusted on the SG signal, revealing difference in the drainage term occurring at the catchment scale or in the SG footprint during winter peak flow events. We then discuss the possible causes that could lead to a lower contribution of the upper compared to the lower part of the catchment to the generation of peak flow. Conclusions are given in Section 5 .

\section{SITE OF STUDY}

\subsection{A multi-instrumented granitic catchment}

The Strengbach catchment is a small $\left(0.8 \mathrm{~km}^{2}\right)$ granitic headwater catchment located in the Vosges massif in the northeastern part of France. It is a mountainous catchment with steep slopes whose altitudes range between $850 \mathrm{~m}$ at the outlet and $1150 \mathrm{~m}$ at the summit, the catchment topography was achieved at a $0.5 \mathrm{~m}$ horizontal resolution with a LiDAR survey made in 2018, with a horizontal and vertical precision of respectively 0.1 and $0.05 \mathrm{~m}$ (Fig. 1). The bedrock mainly consists in Hercynian Ca-poor granite with various level of hydrothermal alteration. Apart from granite, a gneiss body outcrops along the northern crest line (Fig. 1). Bedrock is covered by a granitic saprolite whose thickness should vary between 1 and $9 \mathrm{~m}$ (El Gh'Mari 1995). This thin superficial layer is expected to host the active aquifer, that is, the main contributor to the permanent stream draining the catchment (Weill et al. 2017, 2019; Lesparre et al. 2020). Forest cover mainly consists in spruces (Piceas abies L., 80 per cent) and beeches (Fagus sylvatica L., 20 per cent). Climate is temperate of oceanic-mountainous type. For a comprehensive description of Strengbach catchment lithology, climate, soil and vegetation cover we refer to Pierret et al. (2018).

Strengbach catchment hydrometeorological fluxes (i.e. rain, outflow and evapotranspiration) are monitored by OHGE (Observatoire Hydro-Géochimique de 1'Environnement, http://ohge.unistra.fr/) since 1986. OHGE is part of the OZCAR (French network of Critical Zone Observatories: Research and Applications) network for the study of the CZ (Gaillardet et al. 2018). In the framework of the CRITEX project (https://www.critex.fr), a new SG iGrav\#30 from GWR Instruments Inc. was installed in 2017 June at the summit of the Strengbach catchment at an altitude of $1104 \mathrm{~m}$ in a building with power and internet connection, in the vicinity of a meteorological station (Fig. 1). The SG is installed on the edge of a $8.4 \mathrm{~m} \times$ $4.4 \mathrm{~m}$ shelter with concrete foundations but without gravimetric pillar (Fig. 1). The SG test mass is located $0.236 \mathrm{~m}$ above the ground. The location of the AG measurements (FG5) and the reference station of the repetition network of relative spring meters (CG5) are also shown on Fig. 1. The SG station is located on the summit of the Strengbach catchment so that all of WSC are occurring below the SG and hence contribute in a cumulative way to the measured gravity signal. The SG integrates WSC occurring in the kilometric footprint area which includes two other watersheds: the Bourgade catchment and the Saint-Pierre-sur-1'Hâte catchment (Fig. 1). 


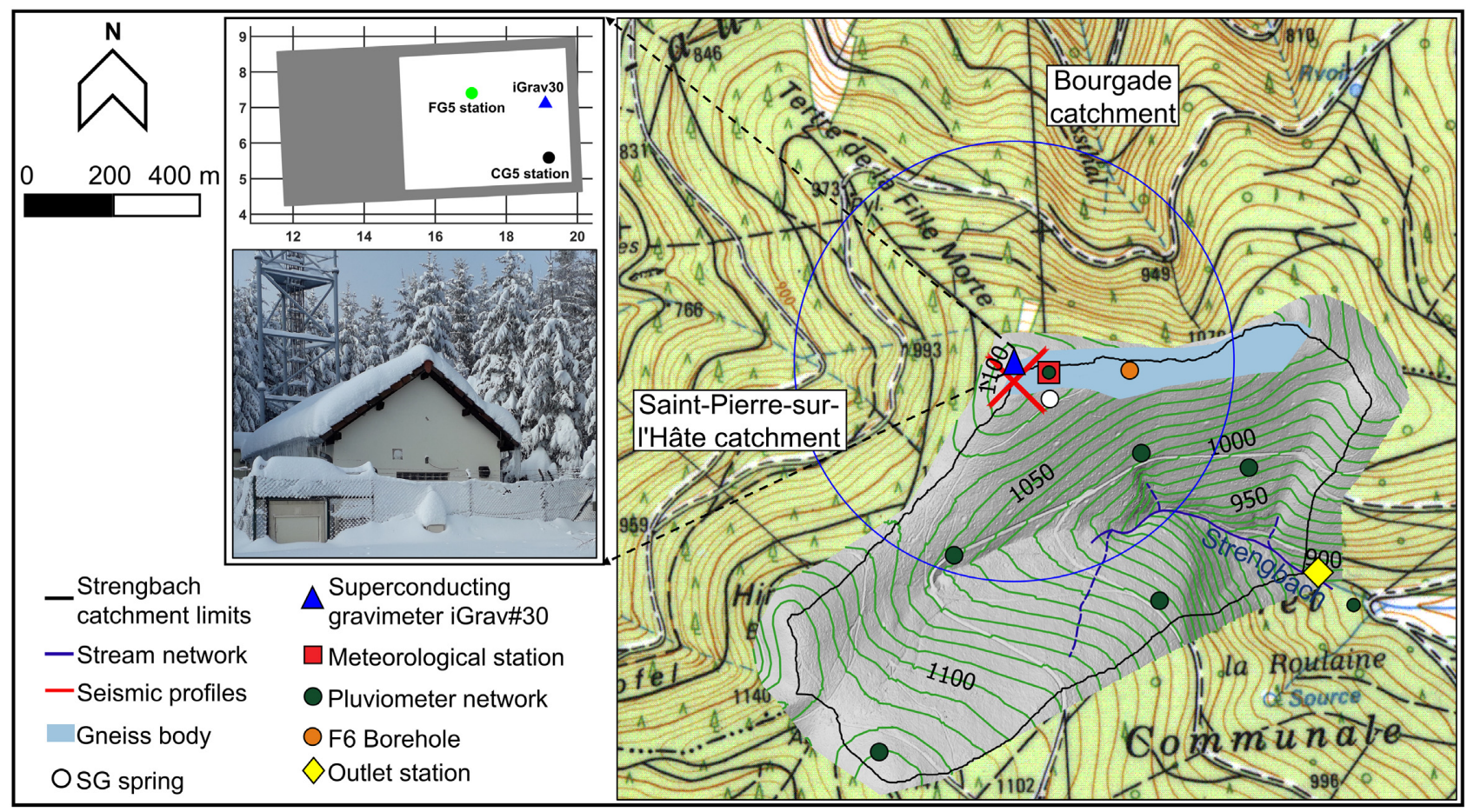

Figure 1. Strengbach catchment instrumentation map. Left: outside and inside view of the shelter that houses the SG (photography taken in 2021 January). Right: topography map of the studied area. The grey zone which includes the Strengbach catchment corresponds to the precise topography model assessed from the 2018 LIDAR survey, the background map (IGN 3718OT) is from the French 'Institut Géographique National' (IGN), last update 2020 March. Altitude difference between iso level lines is $10 \mathrm{~m}$. The blue circle delimits the area located at less than $500 \mathrm{~m}$ from the SG.

\subsection{Hydro-meteorological characteristics}

The Strengbach catchment is a topographic catchment so that the watershed limits correspond to the crest lines. In the absence of any known impermeable body throughout the catchment, we assume that water entering into the Strengbach catchment is fully collected at the outlet, that is, we consider the Strengbach catchment as a hydrographic catchment. CWB (see solid black line, Fig. 2) is then given by the water balance equation:

CWB $(t)=P^{\text {cum }}(t)-$ Streamflow $^{\text {cum }}(t)-\operatorname{AET}^{\text {cum }}(t)$

where $\mathrm{P}^{\text {cum }}$ refers to the cumulated catchment-average precipitation (see the bar chart, Fig. 2 and Appendix B). Streamflow ${ }^{\text {cum }}$ corresponds to the cumulated streamflow (see blue line, Fig. 2) measured at a 10 -min time step by the catchment outlet station (yellow diamond, Fig. 1), note that the flow measured by the outlet station (in $\mathrm{m}^{3} \mathrm{~d}^{-1}$ ) is converted into $\mathrm{mm}$ of water per day by taking into account the catchment area. AET $^{\text {cum }}$ refers to the cumulated actual evapotranspiration (see green line, Fig. 2). Precipitation is measured at a 10 -min time step at the summit weather station which is located $40 \mathrm{~m}$ away from SG (red square, Fig. 1) by a $1 \mathrm{~m}$ high automated rain gauge. When temperature measured at the summit weather station is below $0{ }^{\circ} \mathrm{C}$, precipitation is considered as snow. Snow height is also measured at the summit weather station with a $5 \mathrm{~cm}$ precision at a daily time step thanks to daily images provided by a camera pointing at a snow gauge, the snow water equivalent is then computed from the snow fall and the snow height (see Appendix A for a detailed description of the method). Catchment-average precipitation $P$ is computed by scaling summit weather station rain gauge data with a regionalization factor which accounts for rain spatial heterogeneity and effect of measurement height (see Appendix B for a detailed description of the method).
Solar radiation, temperature, humidity and wind speed are monitored at the summit weather station. These data are used to estimate the actual evapotranspiration at a daily time step from the BILJOU model that takes into account the forest cover and soil type (Granier et al. 1999).

Strengbach streamflow is characterized by major peak flow events occurring during the winter season or at the end of it, in coincidence with major precipitation events whose effect can be amplified by the melting of the intermittent snow cover. In this study we focus on the 2018 January 5-23 peak flow events which reached $21.8 \mathrm{~mm} \mathrm{~d}^{-1}$ (equivalent to $\left.0.202 \mathrm{~m}^{3} \mathrm{~s}^{-1}\right)$ and $24.2 \mathrm{~mm} \mathrm{~d}^{-1}\left(0.224 \mathrm{~m}^{3} \mathrm{~s}^{-1}\right)$, respectively, and on the 2019 March 16 peak flow event which reached $15.1 \mathrm{~mm} \mathrm{~d}^{-1}\left(0.140 \mathrm{~m}^{3} \mathrm{~s}^{-1}\right.$, see Table 1 and the black arrows on Fig. 2). For comparison, the mean streamflow for the 2017 to 2020 January period is $1.7 \mathrm{~mm} \mathrm{~d}^{-1}\left(0.016 \mathrm{~m}^{3} \mathrm{~s}^{-1}\right)$. These events were caused by the major precipitation events (snowfall and rainfall) and by the snowpack melting occurring in the days preceding the peak flows: at the summit weather station (Fig. 1), the snowpack melting represents 40 per cent (for the 2018 January 23 event) to 56 per cent (for the 2019 March 16 event) of the pre-event cumulated precipitation (Table 1). Note that the melting of the pre-event snowpack did not contribute significantly to the 2018 January 23 and the 2019 March 16 events because the pre-events snow heights were very small (equivalent to 1 and $6.3 \mathrm{~mm}$ of snow water equivalent, respectively, see Table 1). For the 2018 January 5, the contribution of the pre-event snowpack melting is higher because the snowpack was larger (equivalent to $23.4 \mathrm{~mm}$ of water, see Table 2), but its contribution is still secondary compared to the cumulated precipitation falling in the days preceding the peak flow $(127.7 \mathrm{~mm}$, see Table 1).

A previous study from Ladouche et al. (2001) investigated the peak flow generation processes within the Strengbach 

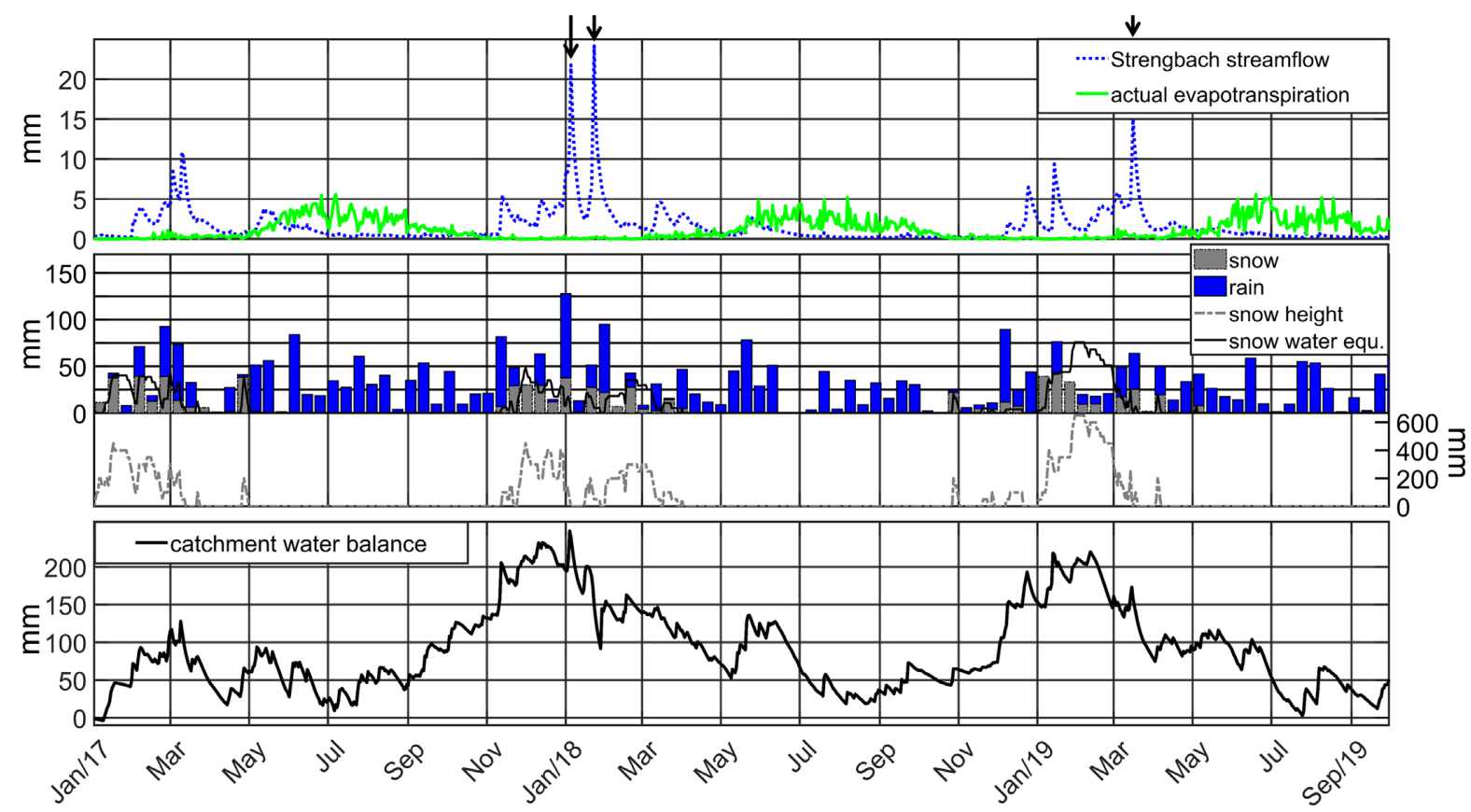

Figure 2. Top: Strengbach catchment daily streamflow and actual evapotranspiration. Middle: rain and snow precipitation cumulated over a 15-d time step (bar plot), daily snow height (grey dashed curve) and snow water equivalent (black curve). Bottom: daily Strengbach catchment water balance. Arrows indicate the 2018 January 5 and 23 and 2019 March 16 peak flow events.

Table 1. Hydrological characteristics of the 2018 January 5 and 23, and the 2019 March 16 peak flow events. The 'peak flow onset' refers to the onset of streamflow rising, and 'peak flow' refers to the time of maximal streamflow. SnowWaterEqu. refers to the amount of water stored in the snowpack (see Appendix A), SnowMelt cum and $P_{\text {cum }}$ refers respectively to the cumulated snowmelt water produced by the melting of the snowpack (see Appendix A) and to the cumulated precipitation (including snowfall and rainfall) during the period ranging from $2 \mathrm{~d}$ before the peak flow onset to the peak flow.

\begin{tabular}{|c|c|c|c|c|c|c|c|}
\hline Flood event & Period & Date & Streamflow $\left(\mathrm{mm} \mathrm{d}^{-1}\right)$ & $\begin{array}{l}\text { SnowWater Equ. } \\
(\mathrm{mm})\end{array}$ & $\begin{array}{l}\text { SnowMelt }{ }_{\text {cum }} \\
(\mathrm{mm})\end{array}$ & $\mathrm{P}_{\text {cum }}(\mathrm{mm})$ & $\begin{array}{c}\text { SnowMelt } \text { cum } / P_{\text {cum }} \\
\text { (per cent) }\end{array}$ \\
\hline \multirow[t]{2}{*}{2018 January 5} & $\begin{array}{c}2 \mathrm{~d} \text { before peak flow } \\
\text { onset }\end{array}$ & 2017 Dec 27 & 4.4 & 23.4 & 55.3 & 127.7 & 43 \\
\hline & Peak flow & 2018 Jan 05 & 21.8 & 0 & & & \\
\hline 2018 January 23 & $\begin{array}{c}2 \mathrm{~d} \text { before peak flow } \\
\text { onset }\end{array}$ & 2018 Jan 15 & 2.6 & 1 & 23.2 & 58.2 & 40 \\
\hline \multirow[t]{3}{*}{2019 March 16} & $\begin{array}{c}2 \mathrm{~d} \text { before peak flow } \\
\text { onset }\end{array}$ & 2019 Mar 12 & 4.2 & 6.3 & 31 & 55.7 & 56 \\
\hline & Peak flow onset & 2019 Mar 14 & 4.9 & 24.8 & & & \\
\hline & Peak flow & 2019 Mar 16 & 15.1 & 0 & & & \\
\hline
\end{tabular}

Table 2. Comparison between $\mathrm{SG}_{\mathrm{wsc}}$, CWB and regional contribution of hydrology models MERRA2 and GLDAS2. Correlation coefficients are given with the 99 per cent confidence level interval (see parenthesis). The annual cycle is fitted on SGWSC using the Matlab function provided by Greene et al. (2019).

\begin{tabular}{|c|c|c|c|c|c|}
\hline \multirow{2}{*}{\multicolumn{2}{|c|}{$\begin{array}{c}\mathrm{SG}_{\mathrm{wsc}} \text { global hydrology correction } \\
\text { Hydrology model }\end{array}$}} & \multicolumn{2}{|c|}{ MERRA2 $_{\text {global }}$} & \multicolumn{2}{|c|}{ GLDAS2 global } \\
\hline & & \multirow{2}{*}{$\frac{\text { MERRA } 2_{\text {regional }}}{63}$} & \multirow{2}{*}{$\frac{\text { CWB }}{40}$} & \multirow{2}{*}{$\frac{\text { GLDAS } 2_{\text {regional }}}{62}$} & \multirow{2}{*}{$\frac{\text { CWB }}{46}$} \\
\hline RMSE SGWSC versus & $\mathrm{SG}_{\mathrm{WSC}}^{\mathrm{Max}}$ & & & & \\
\hline hydrology model (mmWater) & $\mathrm{SG}_{\mathrm{WSC}}^{\mathrm{Min}}$ & 68 & 33 & 43 & 34 \\
\hline Correlation coeff. $\mathrm{SG}_{\mathrm{wsc}}$ vers & rology model & $0.73(0.690 .78)$ & $0.82\left(\begin{array}{lll}0.79 & 0.85)\end{array}\right.$ & $0.58(0.520 .64)$ & $0.80\left(\begin{array}{lll}0.76 & 0.83)\end{array}\right.$ \\
\hline Correlation coeff. $\mathrm{SG}_{\mathrm{wsc}}$ (cor & from $\mathrm{SG}_{\mathrm{WSC}}$ & $0.06(-0.030 .16)$ & $0.54(0.470 .60)$ & $0.20\left(\begin{array}{lll}0.11 & 0.29\end{array}\right)$ & $0.48\left(\begin{array}{ll}0.41 & 0.55\end{array}\right)$ \\
\hline
\end{tabular}
annual cycle) versus hydrology model (corrected from $\mathrm{SG}_{\mathrm{WSC}}$ annual cycle)

catchment at the event timescale. The authors demonstrated that peak flow resulting from an intense storm event occurring during the low flow period (in 1994 May) was mainly caused by runoff coming from the downstream part of the Strengbach catchment (zones 2 and 3 on fig. 1 of Ladouche et al. 2001), while the hydrological contribution from the upper part of the catchment was negligible (zone 1 on fig. 1 of Ladouche et al. 2001). The weak contribution of the upper part of the catchment (zone 1) was attributed to dry soils that need to reconstitute their storages before contributing to streamflow generation. 
At longer timescales, during the 2004-2007 period, the contribution of the zones 1 and 2 to the streamflow measured at the catchment outlet varies from 5 to 30 per cent, while it represents as much as 68 per cent of the catchment area, so it shows that the upper part of the catchment is also less contributive to the streamflow generation than the downstream part (OHGE).

Based on the same 1994 May storm event than the one described by Idir et al. (1999) and Ladouche et al. (2001), showed that the wetland zone located in the downstream part of the catchment (fig. 1 of Ladouche et al. 2001), supplied as much as 25-29 per cent of the streamflow measured at the outlet station while it occupied only 2 per cent of the catchment area. This wetland zone is therefore particularly reactive and contributive during storm flow events. Geochemical and isotopic studies of the different springs and streams from the Strengbach catchment conducted on two hydrological cycles from 2004 to 2006 also confirmed that the hydrologic contribution of the wetland zone increases when discharge increases (Pierret et al. 2014).

\subsection{Underground structure around the SG station}

The SG station is located on a gneiss body (Fig. 1). Nearby, the F6 borehole (located $250 \mathrm{~m}$ west from SG station, Fig. 1) is located on the same gneiss body and provides access to the local $\mathrm{CZ}$ vertical structure down to a depth of $120 \mathrm{~m}$. For the sake of simplicity, we adopt a three-layer conceptual model of the CZ structure (e.g. Holbrook et al. 2014, 2019; Flinchum et al. 2018) which is based on a F6 well logging. These layers are identified from the top down as: the saprolite layer that is intensively weathered and friable; the weathered bedrock layer with higher fracture density and higher degree of weathering and the protolith or fresh bedrock layer with minor alteration and few fractures. In F6 borehole, a sharp transition is observed at $2.4 \mathrm{~m}$ of depth where a mixture of sand and friable rock turns into fractured gneiss. This interface corresponds to the saprolite-weathered bedrock transition. At a depth of $40 \mathrm{~m}$, fractured gneiss is replaced by granite episodically interspersed with hydrologically conductive fractures, sometimes surrounded by intense alteration zones. The transition between weathered bedrock and protolith seems to be localized above the core bottom (120 m depth). Because the $\mathrm{CZ}$ structure is highly variable spatially (e.g. Flinchum et al. 2018), the underground structure beneath SG cannot be inferred by extrapolating directly the F6 borehole stratigraphy. We rather used active seismic refraction surveys to estimate the saprolite depth around the SG station. For this purpose, two perpendicular $180 \mathrm{~m}$ long seismic profiles were acquired in 2019 August (see red lines on Fig. 1 and Appendix C). One is following the crest line while the second follows the direction of maximal slope (see Appendix $\mathrm{C}$ for a detailed description of the method). In the following we consider $3 \mathrm{~m}$ as a characteristic thickness for the saprolite layer within $100 \mathrm{~m}$ from SG station as inferred from the seismic profile analysis.

In a steep forested catchment (Eel River Critical Zone Observatory, Northern California Coast Ranges, USA), Rempe (2016) could access to the vertical structure of WSC thanks to repeated neutron probe surveys within a well network. From these measurements, the author could propose a conceptual model of rock moisture storage mechanisms (fig. 5.20 from Rempe 2016) which distinguishes from the top down as: a chronically unsaturated shallow zone with large WSC, a seasonally saturated zone with low WSC and a chronically saturated zone with negligible WSC below the aquifer base level. Then, based on the findings by Rempe (2016), we argue that the subsurface structure, as assessed by seismic tomography around the $\mathrm{SG}$, can bring indirect constrains on the distribution of WSC. If the model of Rempe (2016) also applies to the ridge of the Strengbach catchment, most WSC should occur in the saprolite (which corresponds to the first $3 \mathrm{~m}$ in the SG area) and in the upper part of the weathered bedrock (corresponding to the first ten of metres in the SG area), as it was shown in a similar context by Creutzfeldt et al. (2010b) at the Wettzell observatory (Germany) and Van Camp et al. (2006) at the Membach observatory (Belgium).

\section{DATA PROCESSING}

\subsection{Extraction of SG local hydrological loading}

The SG signal contains tides and polar motion contribution, as well as hydrological and atmospheric loading contributions resulting from both regional and global scales (Boy et al. 2002; Llubes et al. 2004; Creutzfeldt et al. 2008; Longuevergne et al. 2009). We use the atmospheric and hydrological loading product computed at the EOST loading service (http://loading.u-strasbg.fr). Loading is available for a regional radius of $0.10^{\circ}$ (equivalent to $11 \mathrm{~km}$ ) or $0.25^{\circ}$ (equivalent to $27.5 \mathrm{~km}$ ). So, in this study, in consistence with available loading products, we defined the regional area as a circle with a radius of $11-\mathrm{km}$ centred on SG location, while the global area includes the rest of the Earth surface. Note that ground uplift or subsidence may also impact gravity, but no significant trend has been observed by the RENAG permanent GNSS station named AUBU operating $40 \mathrm{~m}$ away from iGrav30 (Henrion et al. 2020).

The SG was calibrated using a 5-d long series of side by side observations made in 2018 May using an absolute gravimeter FG5\#206 from Micro-g Lacoste Inc. (Rosat et al. 2018). The resulting SG calibration factor is $-919 \pm 3 \mathrm{~nm} \mathrm{~s}^{-2} \mathrm{~V}^{-1} \mathrm{SG} 1$-s samples are decimated into 1-min samples using a standard low pass filter. Then perturbations in the SG signal resulting from lightning spikes, visits in the SG shelter and earthquakes are removed using the remove-restore technique (Hinderer et al. 2015). The SG signal is then corrected from polar motion; the tidal contribution is removed using adjusted diurnal to ter-diurnal oceanic and solidEarth tides, nominal annual to half-monthly solid-Earth tides (factor 1.16 and lag $0^{\circ}$ ) and annual to half-monthly oceanic tides from the hydrodynamic FES2014b ocean model (Lyard et al. 2006). For a comprehensive description of the specific tidal correction applied here, we refer to Chaffaut et al. (2020). The SG instrumental drift was estimated based on 3 AG measurements performed with an FG5 absolute gravimeter the 2018 May 28-June 1, the 2019 May 2 and 3 and the 2020 September 3 and 4 in the SG shelter (Fig. 1). In a first step, FG5 sets and SG gravity signal are corrected from tides, polar motion and regional atmospheric signal (using a regional atmospheric admittance factor of $-2.345 \mathrm{~nm} \mathrm{~s}^{-2} \mathrm{~h} \mathrm{~Pa}^{-1}$ ). Then, the SG signal is sampled at the same dates than FG5 sets, and the SG signal is set to zero at the reference time (28-May-2018 13:06:55 UT), which corresponds to the first FG5 set date. Finally, the corrected SG gravity signal is adjusted on the 3 FG5 sets series (i.e. the 2018 May 28-June 1, the 2019 May 2 and 3 and the 2020 September 3 and 4 series) by a weighted linear regression which takes into account FG5 set error, assuming that SG error is negligible (eq. 2):

$\mathrm{AG}_{\text {gravity }}+e=g_{\text {Ref }}+\mathrm{SG}_{\text {gravity }}+\dot{d} \times\left(t-t_{0}\right)$

$\mathrm{AG}_{\text {gravity }}$ and $\mathrm{SG}_{\text {gravity }}$ correspond, respectively, to FG5 sets gravity and SG gravity corrected from polar motion, regional atmosphere and tides (Fig. 3); $t_{0}$ and $g_{\text {Ref }}$ correspond, respectively, to the refer- 


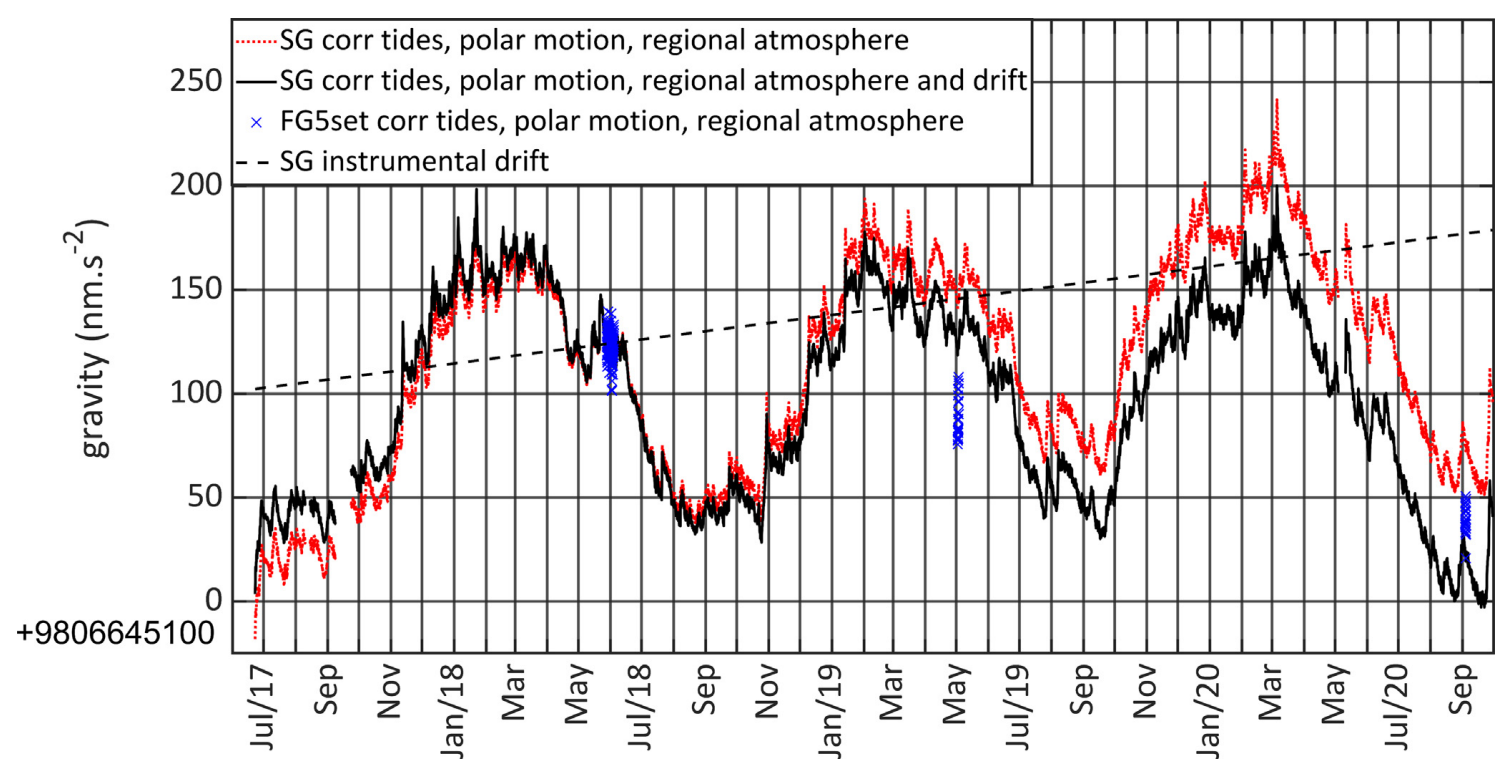

Figure 3. Estimation and correction of SG instrumental drift with FG5 set data.

ence time (28-May-2018 13:06:55 UT) and to the adjusted reference AG value. $\dot{d}$ corresponds to SG instrumental drift rate and $e$ is a residual. The choice of a linear model for the instrumental drift is reasonable because the $3 \mathrm{AG}$ measurements were performed at least one year after the installation of the SG, so that no more initial exponential drift is expected to disrupt the SG signal at the times of AG measurements (Hinderer et al. 2015). At these times, only a nearly linear long-term instrumental drift remains, which is not discernable from a long-term exponential drift for time-series shorter than $10 \mathrm{yr}$ (Va $\mathrm{mp}$ and Francis 2006). The adjusted drift rate is $23.36 \pm 1.4 \mathrm{c} \ldots \mathrm{s} \mathrm{s}^{-2} \mathrm{yr}^{-1}$ (see dotted black line, Fig. 3) and the reference gravity value is $9806645274 \mathrm{~nm} \mathrm{~s}^{-2}$. Note that the adjusted drift rate is very similar to the long-term drift rate observed at J9 Observatory ( $26 \mathrm{~nm} \mathrm{~s}^{-2} \mathrm{yr}^{-1}$ ) near Strasbourg where iGrav30 was operated before being transported cold in a short time (a few hours) to the Strengbach station.

The second (2019 May) and - to a lesser extent - the third (2020 September) AG measurement are off the drift-corrected SG timeseries (average misfit $e$ is $-34 \mathrm{~nm} \mathrm{~s}^{-2}$ in 2019 May and $18 \mathrm{~nm} \mathrm{~s}^{-2}$ in 2020 September, while it is only $4 \mathrm{~nm} \mathrm{~s}^{-2}$ for the 2018 May and June AG measurement), even when considering the FG5 uncertainty range. The first AG measurement has more weight because it lasted longer ( $5 \mathrm{~d}$ ) than the following measurements $(1 \mathrm{~d})$, which explains why it is closer to the SG time-series. The remaining-weakdiscrepancies between AG and drift-corrected SG measurements could results from the fact that both instruments are not exactly measuring at the same location: FG5 is measuring at $1.308 \mathrm{~m}$ above the ground at the centre of the shelter, while the SG is measuring at $0.236 \mathrm{~m}$ at the edge of the shelter. As a result, the SG and the FG5 could measure slightly different gravity signal (i.e. at the level of $10 \mathrm{~nm} \mathrm{~s}^{-2}$ ).

For the rest of the study, one has to keep in mind that, while being not perfectly constrained, the long-term SG instrumental drift is small and would not affect the results of this study because: (i) we are discussing seasonal or subseasonal gravity changes occurring in 2018 and 2019, that is, the initial exponential drift which is possibly affecting the first months of the SG time-series (at most until 2017 October and November) has vanished and became linear, and (ii) we do not discuss the geophysical trend of the SG signal. Additional
AG measurements are planned on a yearly basis, which will further improve the drift estimation.

Global hydrological contributions (see blue line on Fig. 4b) that is, the sum of global Newtonian attraction term and elastic deformation term, are estimated by the convolution of loading Green's functions with global hydrological model water height (Llubes et al. 2004; Boy \& Hinderer 2006). We extract the global hydrological loading computed at EOST (http://loading.u-strasbg.fr/) based on global hydrology models MERRA2 (Modern-Era Retrospective analysis for Research and Applications, version 2, Gelaro et al. 2017) and GLDAS/Noah version 2.1 (Global Land Data Assimilation system, Rodell et al. 2004), referred as GLDAS2 in the following. MERRA2 products are available at $1-\mathrm{hr}$ time step and $50 \mathrm{~km}$ resolution while GLDAS2 products are available at $3-\mathrm{hr}$ time step and $30 \mathrm{~km}$ resolution.

Global atmospheric loading is the sum of global Newtonian attraction term and elastic deformation term. The global elastic deformation term is computed by convolving Earth elastic Green's functions with ECMWF atmospheric model surface pressure assuming inverted barometer for the response of the oceans to pressure forcing (Boy et al. 2002). The global attraction term is computed by convolving attraction Green's function with $2.5 \mathrm{D}$ atmospheric density rebuilt from ECMWF surface pressure (Boy et al. 2002). Here, we specifically developed a regional atmospheric loading model which explicitly considers the topography effect and is based on SG local atmospheric pressure measurement. Local atmosphere is defined as a cylinder centered on SG location with a radius of $11 \mathrm{~km}$ (in consistence with available loading products at the EOST loading service, http://loading.u-strasbg.fr) whose base mimics the topography and whose top is located $50 \mathrm{~km}$ above topography. Regional atmosphere is discretized into prisms (horizontal dimension of $40 \mathrm{~m}$ $\times 40 \mathrm{~m}$, variable vertical dimension: from $5 \mathrm{~m}$ at the surface up to $100 \mathrm{~m}$ for an altitude of $50 \mathrm{~km}$ ), pressure in each prism is derived from hydrostatic equilibrium and density is then computed using the perfect gas law. The temperature gradient used in the troposphere (altitude ranging between 0 and $12 \mathrm{~km}$ ) is $-6.49{ }^{\circ} \mathrm{K} \mathrm{km}^{-1}$ while the temperature gradient in the stratosphere (altitude ranging between 12 and $50 \mathrm{~km}$ ) is set to zero. We use a constant surface temperature of $280.2^{\circ} \mathrm{K}$ which corresponds to the average temperature 

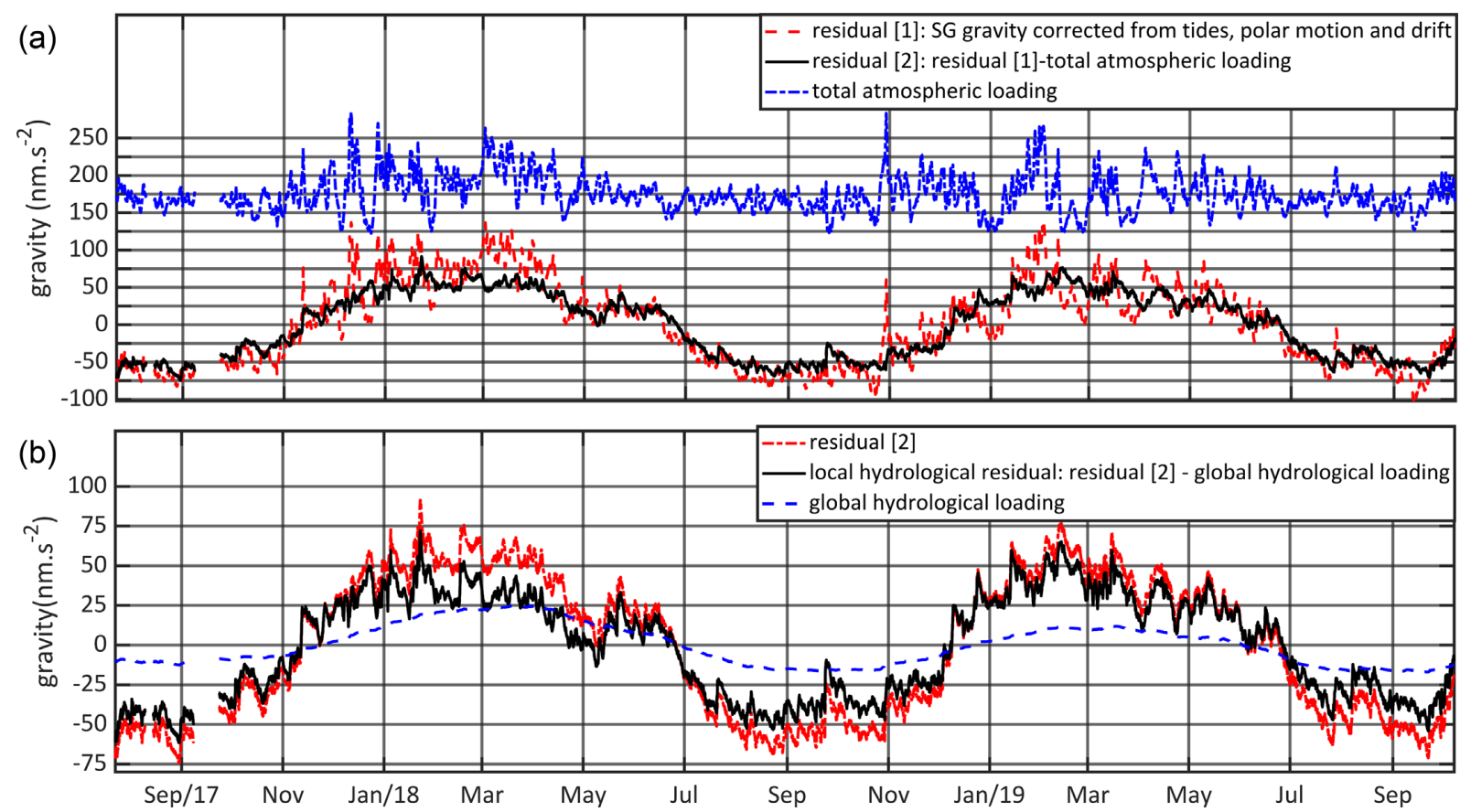

Figure 4. Processing steps for extracting the local hydrological residual. (a) SG gravity corrected from tides, polar motion and instrumental drift (black curve) versus total hydrological residual (red curve). (b) Total hydrological residual (black curve) versus local hydrological residual (i.e. total hydrological residual corrected from MERRA2 global hydrology, red curve).

measured at the SG nearby weather station over the period extending from 2017 June to 2019 September (Fig. 1). Regional atmospheric admittance $A_{\text {regional }}^{\text {Atm }}$ is then computed by summing up the gravity effect of all prisms using the integration method described in Leirião et al. (2009). Regional atmospheric loading is then given by:

AtmLoad $_{\text {regional }}=A_{\text {regional }}^{\mathrm{Atm}} * P$ atm $_{\mathrm{SG}}$

The regional atmospheric admittance $A_{\text {regional }}^{\text {Atm }}$ value we found is $-2.345 \mathrm{~nm} \mathrm{~s}^{-2} \mathrm{~h} \mathrm{~Pa}^{-1}$. Note that this value is relatively low compared to the usually used empirical admittance value of about $-3 \mathrm{~nm} \mathrm{~s}^{-2} \mathrm{~h} \mathrm{~Pa}^{-1}$ (Fores et al. 2017; Mikolaj et al. 2019). This results from two facts: (i) $A_{\text {regional }}^{\text {Atm }}$ only integrates the atmospheric loading effect up to $11 \mathrm{~km}$ from the gravimeter, (ii) the SG is located at $1104 \mathrm{~m}$ of altitude, so the overlying atmosphere is thinner and its effect is partly compensated by the overlying atmosphere (assuming that $\mathrm{SG}$ is located at $0 \mathrm{~m}$ of altitude, the same computation would give a value of $-2.703 \mathrm{~nm} \mathrm{~s}^{-2} \mathrm{~h} \mathrm{~Pa}^{-1}$ for $A_{\text {regional }}^{\text {Atm }}$ ). The rest of the atmospheric loading effect (i.e. coming from a horizontal distance greater than $11 \mathrm{~km}$ ) is accounted for by the global atmospheric load-

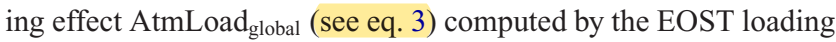
service from the ECMWF global atmospheric model. The total (i.e. regional and global) atmospheric loading (see blue line on Fig. 4a) simply corresponds to the sum of regional and global loading:

AtmLoad $_{\text {total }}=$ AtmLoad $_{\text {regional }}+$ AtmLoad $_{\text {global }}$

\subsection{Effect of the WSC spatial distribution on the SG signal}

The scale factor that links the SG local hydrological loading signal to WSC is the hydrological admittance expressed in $\mathrm{nm} \mathrm{s}^{-2} \mathrm{~mm} \mathrm{Water}^{-1}$. At the timescale of precipitation events (i.e. at a daily timescale), the rainfall admittance is a proxy of the hydrological admittance. Rainfall admittance is defined as the ratio between observed gravity step and rain amount (Imanishi et al.
2006; Meurers et al. 2007; Hector et al. 2014; Fores et al. 2017). Intense rain events produce measurable step-like variations in gravity (Fig. 5b) caused by a fast and superficial increase in soil water storage. At short timescale, the infiltrated rainwater is fully stored at shallow depth and there is no water beneath the observatory building because lateral and vertical transfer have no time to happen. As a result, instantaneous rainfall admittance only depends on the topography, the size, and the location (i.e. above or below ground) of the observatory building. Then, water starts to redistribute vertically and laterally inducing a time-variable gravity signal.

Here, rainfall admittance is defined as the slope of the best linear model passing through a set of intense and well-defined rain events (i.e. whose duration does not exceed $1 \mathrm{~d}$ ). We compute the rainfall admittance $A_{\text {rain }}$ based on a selection of 39 rain events (snow fall events are disregarded) that presents a rain amount larger than $7 \mathrm{~mm}$, average duration of these rain events is $11 \mathrm{hr}$ (Fig. 5a). Such rain events are clearly correlated with gravity steps measured by the $\mathrm{SG}$ (Fig. 5b). We found a value of $0.45+0.08 \mathrm{~nm} \mathrm{~s}^{-2} \mathrm{~mm} \mathrm{Water}^{-1}$ for $A_{\text {rain }}$. Fores et al. (2017) showed a systematic increase of $A_{\text {rain }}$ in the days following the major rain events, which they attribute to water vertical percolation. We do not observe such a change in our data. There is therefore no evidence of significant vertical water percolation or converging water lateral flux beneath the observatory building in the days following the rain events. Note that $A_{\text {rain }}$ is significantly larger than the values found for a gravimetric station located at Djougou (Benin) on a flat area and with comparable umbrella effect $\left(0.22 \mathrm{~nm} \mathrm{~s}^{-2} \mathrm{~mm} \mathrm{Water}^{-1}\right.$, Hector et al. 2014), showing that the summit location of SG significantly amplifies the hydro-gravimetric signal (see Appendix D).

Based on the a priori information on the plausible WSC depth range around the SG station (see Section 2.3), we performed numerical experiments to assess the effect of the WSC distribution on the SG signal and to check whether the rainfall admittance is representative of the topographic admittance. Topographic admittance 

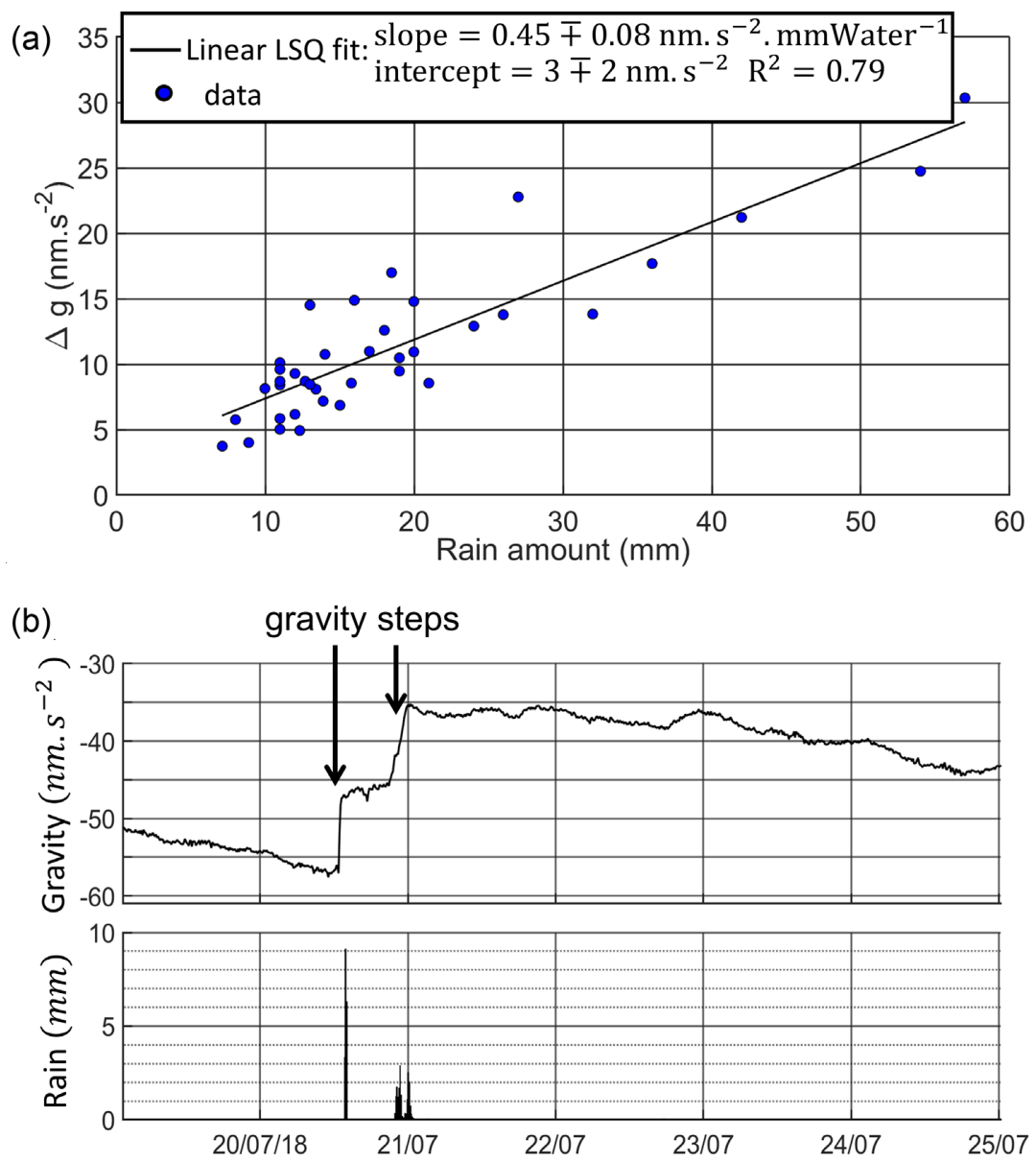

Figure 5. (a) Estimation of SG rainfall admittance by linear regression. (b) Step-like gravity changes induced by intense rain events.

$A_{\text {topo }}$ is defined as the gravity effect of a water layer of constant thickness distributed following the topography (Creutzfeldt et al. 2008; Longuevergne et al. 2009; Hector et al. 2014). Here, we define the topographic admittance as the gravity effect of a water layer of thickness $d$ and density $\rho$ such as $\rho\left[\mathrm{kg} \mathrm{m}^{-3}\right]=\sigma / d$, where $\sigma=100 \mathrm{~kg} \mathrm{~m}^{-2}$ is a nominal water surface density, matching the topography. The water layer is discretized into prisms of variable horizontal dimensions (nested approach as described in Creutzfeldt et al. 2008). Then the gravity effect of the water layer-that is $A_{\text {topo }}$-is obtained by summing up the gravity effect of all prisms up to a distance of $30 \mathrm{~km}$ from the SG (Fig. 5) using the integration method of Leirião et al. (2009), as described in Chaffaut et al. (2020).

The observatory building acts as a mask which prevents water infiltration below the gravimeter and consequently reduces WSC occurring in the close surrounding of the gravity sensor (Creutzfeldt et al. 2010a; Deville et al. 2013; Reich et al. 2019), this effect being referred as the umbrella effect (Creutzfeldt et al. 2008). For modelling the umbrella effect, we computed $A_{\text {topo }}$ by excluding prisms below the shelter, that is, we assume that no WSC is occurring below the shelter. To test the impact of the umbrella effect, we also computed the topographic admittance without taking its effect into account, referred as $A_{\text {topo }}^{\text {No Umbrella }}$ in the following.

We tested the impact of the WSC depth by computing the topographic admittance for different water layer thicknesses. To keep the water surface density $\sigma$ equal to $100 \mathrm{~kg} \mathrm{~m}^{-2}, \rho$ is adjusted to $d$. We considered a layer of thickness $d=0.1 \mathrm{~m}$ and volumetric mass $\rho=1000 \mathrm{~kg} \mathrm{~m}^{-3}$ (i.e. layer depth ranging from the surface down to $0.1 \mathrm{~m}$, red lines, Fig. 6), a layer of thickness $d=3 \mathrm{~m}$ and volumetric mass $\rho=33.33 \mathrm{~kg} \mathrm{~m}^{-3}$ (see blue lines, Fig. 6) and a layer of thickness $d=10 \mathrm{~m}$ and volumetric mass $\rho=10 \mathrm{~kg} \mathrm{~m}^{-3}$ (see black lines, Fig. 6).

The asymptotic value of $A_{\text {topo }}$ is $0.77 \mathrm{~nm} \mathrm{~s}^{-2} \mathrm{~mm} \mathrm{Water}^{-1}$ without considering the umbrella effect, whatever the water thickness (Fig. 6). When taking the umbrella effect into account, the asymptotic value of $A_{\text {topo }}$ is $0.67 \mathrm{~nm} \mathrm{~s}^{-2} \mathrm{~mm} \mathrm{Water}^{-1}$ for the $10 \mathrm{~m}$ thick water layer and $0.59 \mathrm{~nm} \mathrm{~s}^{-2} \mathrm{~mm} \mathrm{Water}^{-1}$ for the $3 \mathrm{~m}$ thick water layer while it drops down to $0.43 \mathrm{~nm} \mathrm{~s}^{-2} \mathrm{~mm} \mathrm{Water}^{-1}$ for the $0,1 \mathrm{~m}$ thick water layer (Fig. 6). Then, as already pointed out by several studies, the impact of the umbrella effect depends on the water depth: the shallower the water, the more prominent the umbrella effect (e.g. Hector et al. 2014; Güntner et al. 2017). Therefore, the asymptotic value of $A_{\text {topo }}$ is also sensitive to WSC depth. Assuming: (i) that WSC mostly occur in the saprolite layer, that is, within depths ranging from the surface up to $9 \mathrm{~m}$ at some locations of the Strengbach catchment (El Gh'Mari 1995) or $3 \mathrm{~m}$ in the surrounding of the SG (see Section 2.2 and Appendix C), and (ii) that WSC are spatially homogeneous, these numerical experiments indicate that $A_{\text {topo }}$ ranges between 0.43 and $0.67 \mathrm{~nm} \mathrm{~s}^{-2} \mathrm{~mm} \mathrm{Water}^{-1}$ if we take the umbrella effect into account. However, one should note that the umbrella effect was modelled using the assumption that no WSC occurs below the SG building, although at least partial WSC may occur below the SG. In this case, $A_{\text {topo }}$ would then be slightly higher than indicated by the numerical experiment. 


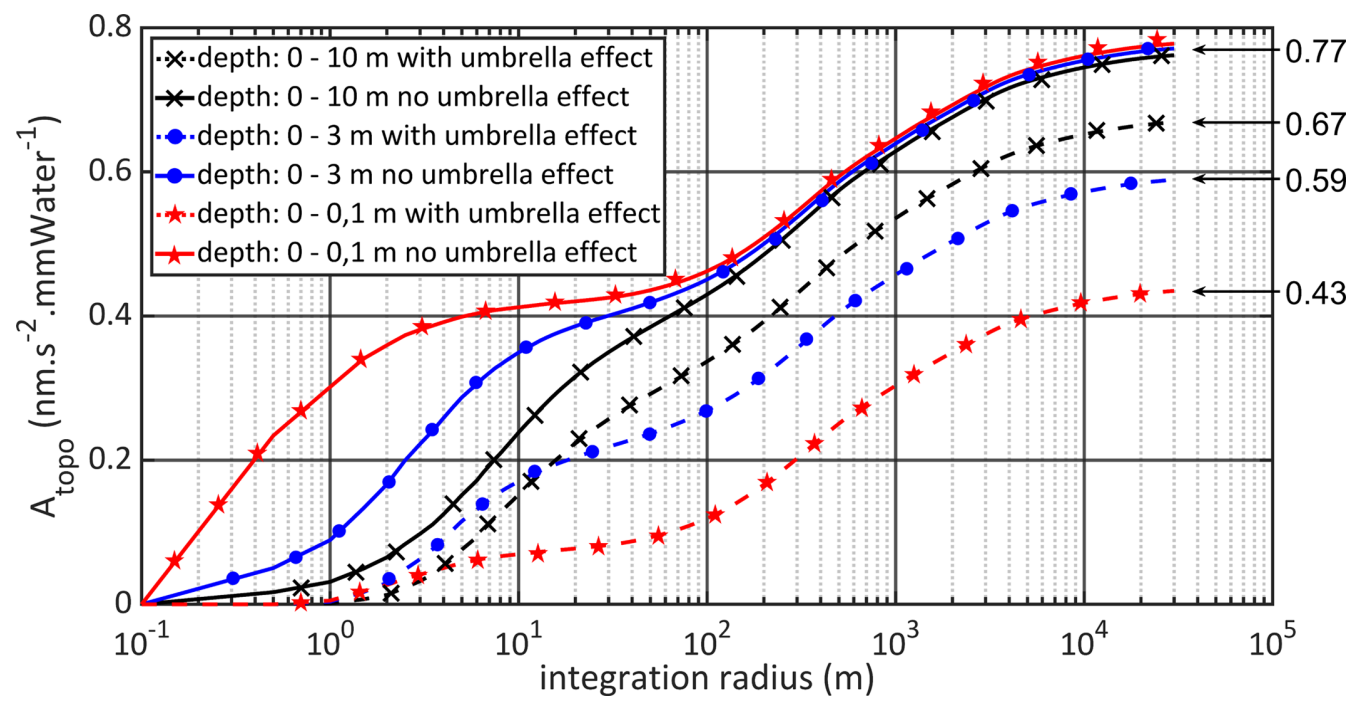

Figure 6. Effect of water depth on the topographic admittance. Dashed lines: SG topographic admittance with umbrella effect for a water layer of nominal surface density $1 \mathrm{~kg} \mathrm{~m}^{-2}$ and a depth range of 0-10 m (black), 0-3 m (blue) or $0.1 \mathrm{~m}$ (red). Solid lines: same as dashed lines but without considering the umbrella effect.

The rainfall admittance $A_{\text {rain }}$ we found (i.e. $0.45+$ $0.08 \mathrm{~nm} \mathrm{~s}^{-2} \mathrm{~mm} \mathrm{Water}^{-1}$ ) is within the range of the computed topographic admittance, and is very close to the $0-0,1 \mathrm{~m}$ deep topographic admittance (i.e. $0.43 \mathrm{~nm} \mathrm{~s}^{-2} \mathrm{~mm} \mathrm{Water}^{-1}$ ). This indicates that fast WSC induced by rain events mostly occurs very close to the surface, at least in the very surrounding of the SG station (within a $80 \mathrm{~m}$ radius).

$A_{\text {rain }}$ is a lower bound $A_{\text {Min }}$ of the hydrological admittance $A$, while $A_{\text {topo }}^{\text {No Umbrella }}\left(0.77 \mathrm{~nm} \mathrm{~s}^{-2} \mathrm{~mm} \mathrm{Water}^{-1}\right)$ is an upper bound $A_{\mathrm{Max}}$ of $A$. In the following, we use A to convert the local hydrological loading signal into WSC (eq. 4), $A$ ranging between $A_{\text {Min }}=0.45 \mathrm{~nm} \mathrm{~s}^{-2} \mathrm{~mm} \mathrm{Water}^{-1}$ and $A_{\mathrm{Max}}=0.77 \mathrm{~nm} \mathrm{~s}^{-2} \mathrm{~mm} \mathrm{Water}^{-1}$ :

$$
\begin{aligned}
\mathrm{SG}_{\mathrm{WSC}} \quad[\mathrm{mmWater}] & =\frac{\mathrm{SG}_{\text {gravity }}\left[\mathrm{nm} \mathrm{s}^{-2}\right]}{A\left[\mathrm{~nm} \mathrm{~s}^{-2} \mathrm{mmWater}^{-1}\right]} \\
\mathrm{SG}_{\mathrm{WSC}}^{\mathrm{Max}} & =\frac{\mathrm{SG}_{\text {gravity }}}{A_{\text {Min }}} \\
\mathrm{SG}_{\mathrm{WSC}}^{\mathrm{Min}} & =\frac{\mathrm{SG}_{\text {gravity }}}{A_{\text {Max }}}
\end{aligned}
$$

Following the same methodology as for $A_{\text {topo }}$, we also computed the nominal effect of snow stored on the SG shelter roof $A_{\text {roof }}$ as the gravity effect of a water layer of constant thickness distributed on the shelter roof (see the snow accumulated on the shelter roof in 2021 January, Fig. 1). We found a value of $0.08 \mathrm{~nm} \mathrm{~s}^{-2} \mathrm{~mm} \mathrm{Water}^{-1}$ for $A_{\text {roof }}$. The gravity effect of the snow stored on the shelter roof $g_{\text {SnowRoof }}$ is given by eq. (6), where $S_{\text {snow }}$ is the snow water equivalent inferred from the ground measurements (see Appendix A):

$g_{\text {SnowRoof }}(t)=A_{\text {roof }} S_{\text {snow }}(t)$

Note that $g_{\text {SnowRoof }}$ is an upper bound of the actual gravity signal produced by the snow on the roof. Indeed, the roof stores less snow than the ground where snow height is actually measured, because snow on the roof is continuously melting due to the heat produced by the SG compressor unit. For the 2017 July-2019 September period considered in this study, maximal value for $S_{\text {snow }}$ is $75 \mathrm{~mm}$, so that maximal $g_{\text {SnowRoof }}$ is no more than $6 \mathrm{~nm} \mathrm{~s}^{-2}$. In the rest of the study, we therefore considered this effect as negligible.

\section{DATA ANALYSIS AND MODELLING}

\subsection{Comparison between SG WSC and CWB}

In this section we compare $\mathrm{SG}_{\mathrm{WSC}}$ with $\mathrm{CWB}$ and with the regional contribution of MERRA2 and GLDAS2 global hydrological models noting that signals have been averaged to zero prior comparison (Fig. 7).

The root mean square error (RMSE) is lower and the correlation coefficient is significantly higher when comparing $\mathrm{SG}_{\mathrm{WSC}}$ to the nearby Strengbach CWB with respect to MERRA2 or GLDAS2 (Fig. 7 and Table 2). Indeed, the MERRA2 and GLDAS2 models present both a low spatial definition (pixel size is $\sim 50 \mathrm{~km}$ for MERRA2 and $\sim 30 \mathrm{~km}$ for GLDAS2) that smooths the storage changes related to small headwater catchments with a strong topography. Note that the MERRA2 regional contribution is significantly better correlated to $\mathrm{SG}_{\mathrm{WSC}}$ than the GLDAS2 one (Table 2), so we consider that MERRA2 is a better proxy of global hydrology as seen by the SG at the Strengbach catchment than GLDAS2. So, in the following, we only discuss the characteristics of the SG signal corrected from the MERRA2 global hydrology.

$\mathrm{SG}_{\mathrm{WSC}}$ reaches its minimal value in 2018 mid-August 2018 and 2019 mid-September, that is, at the end of the dry summer period, while it is maximum in 2018 mid-January and 2019 mid-February, in coincidence with major winter precipitation events falling as snow and/or rain. CWB reaches its minimal value in mid-August and end-July for year 2018 and 2019, respectively, while it is maximum at the beginning of January and mid-February for year 2018 and 2019 , respectively. $\mathrm{SG}_{\mathrm{WSC}}$ range is $254 \mathrm{~mm}\left(\mathrm{SG}_{\mathrm{WSC}}^{\mathrm{Max}}\right)$ or $148 \mathrm{~mm}$ $\left(\mathrm{SG}_{\mathrm{WSC}}^{\mathrm{Min}}\right.$ ) of water for year 2018 and 2019. CWB range is $229 \mathrm{~mm}$ of water for 2018 and $217 \mathrm{~mm}$ of water for 2019. SG $G_{\mathrm{WSC}}$ and CWB have therefore a similar range, noting that CWB range is closer from $\mathrm{SG}_{\mathrm{WSC}}^{\mathrm{Max}}$ range than $\mathrm{SG}_{\mathrm{WSC}}^{\mathrm{Min}}$ range. In addition, both $\mathrm{SG}_{\mathrm{WSC}}$ and CWB reaches a maximal water storage in January to February, and a minimal water storage in August-September (Fig. 7a). Then, $\mathrm{SG}_{\mathrm{WSC}}$ and Strengbach CWB exhibit a similar hydrological cycle in terms of amplitude and temporal pattern. However, one should note that this study is based on only two hydrological cycles, so it will 
(a)
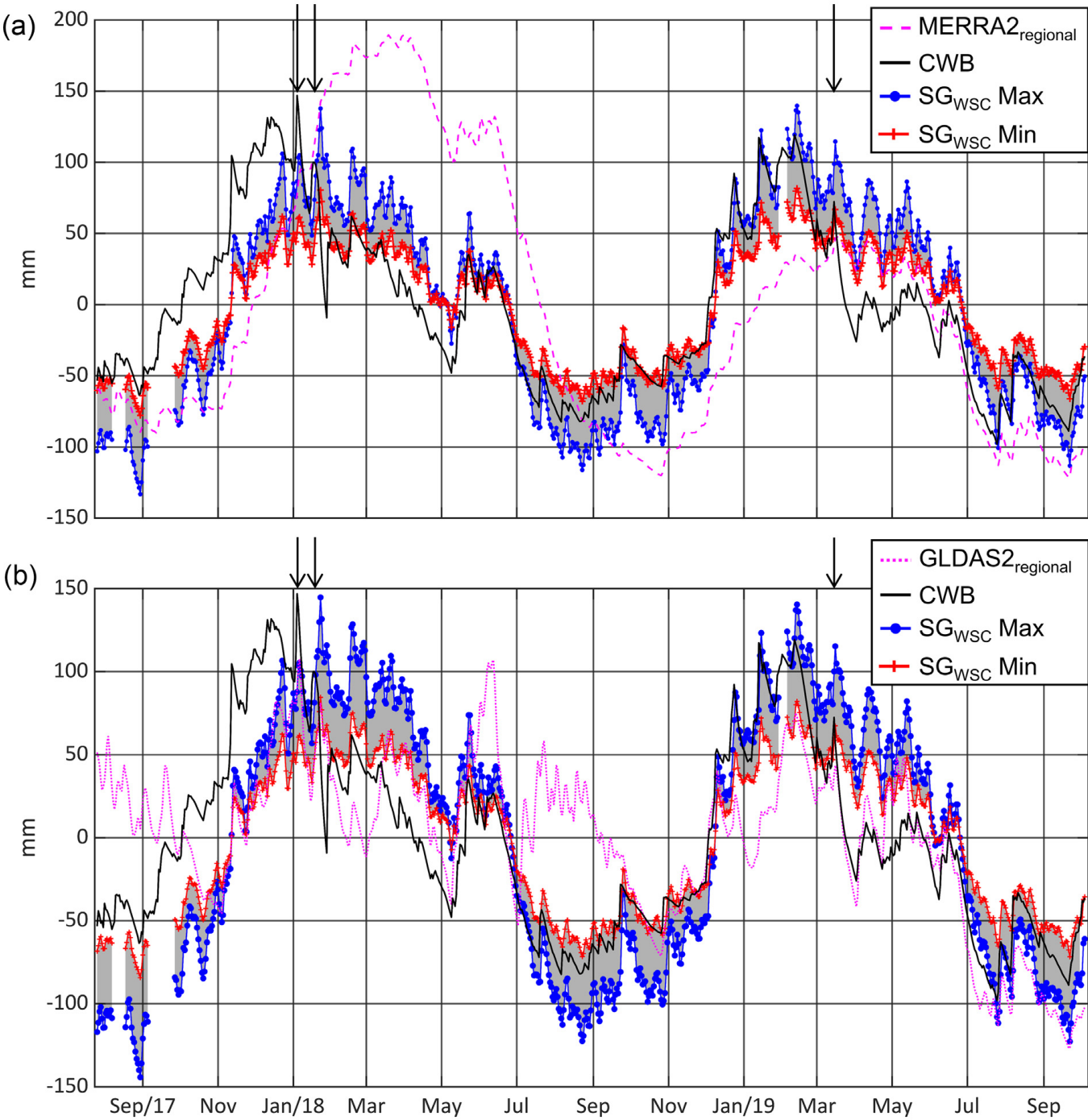

Figure 7. Comparison between SGWSC and hydrology models: (a) SGWSC corrected from MERRA2 global hydrology versus CWB and MERRA2 regional hydrology. (b) SGWSC corrected from GLDAS2 global hydrology vs CWB and GLDAS2 regional hydrology. Arrows indicate 2018 January and 2019 March flood events. $\mathrm{SG}_{\mathrm{WSC}}^{\mathrm{Max}}$ refers to WSC computed using the lower bound of the hydrological admittance $A_{\mathrm{Min}}=0.45 \mathrm{~nm} \mathrm{~s}^{-2} \mathrm{~mm} \mathrm{Water}^{-1}$, while $\mathrm{SG}_{\mathrm{WSC}}^{\mathrm{Min}}$ refers to WSC computed using the upper bound of the hydrological admittance $A_{\mathrm{Max}}=0.77 \mathrm{~nm} \mathrm{~s}^{-2} \mathrm{~mm} \mathrm{Water}{ }^{-1}$.

require validation by extending the comparison between $\mathrm{SG}_{\mathrm{WSC}}$ and CWB when more data are available.

One should recall that the SG signal is the sum of the three surrounding catchments contribution (Strengbach, Bourgade and Saint-Pierre-Sur-l'Hâte, Fig. 1), because of its summit location. Considering a $500 \mathrm{~m}$-radius disc centred on the SG (See the blue circle Fig. 1), from which 60 to 78 per cent of the SG signal comes from (as assessed from the numerical experiments using different hypotheses to compute the topographic admittance, see Section 3.2), the Strengbach catchment accounts for 35 per cent of the disc area, while the Bourgade and Saint-Pierre-Sur-1'Hâte catchment represent the remaining 65 per cent. For a disc radius of $1000 \mathrm{~m}$, from which 72 to 85 per cent of the SG signal comes from, the Strengbach catchment accounts for 25 per cent of the disc surface. Note that even if the SG signal is equally sensitive to the contribution of the upper part of the three neighbouring catchments, we argue that these catchment exhibit a similar hydrological functioning, at least in their upper part because they have similar topography, lithology and climate forcing (please see the discussion in Section 4.3).

From 2018 mid-January to June as well as from 2019 March to June, CWB is outside the $\mathrm{SG}_{\mathrm{WSC}}$ bounds (i.e. it is not comprised between $\mathrm{SG}_{\mathrm{WSC}}^{\mathrm{Min}}$ and $\mathrm{SG}_{\mathrm{WSC}}^{\mathrm{Max}}$, see Fig. 7a). During these periods $\mathrm{SG}_{\mathrm{WSC}}$ remains high while $\mathrm{CWB}$ decrease, and the onset of the CWB decrease coincides respectively with the 2018 January 23 and the 2019 March 16 flood events (Fig 7a). The Strengbach creek flow reaches as much as $24.2 \mathrm{~mm} \mathrm{~d}^{-1}$ for the 2018 January 23 flood event and $15.1 \mathrm{~mm} \mathrm{~d}^{-1}$ for the 2019 March 16 flood event (Fig. 2), while average annual discharge is $1.7 \mathrm{~mm} \mathrm{~d}^{-1}$ for year 2018 . We attribute the discrepancies between $\mathrm{SG}_{\mathrm{WSC}}$ and Strengbach CWB to hydrological processes that differs between the upper part of the hydro-system and those occurring at the catchment scale. In particular, the drainage term representative of the SG footprint area should be significantly lower than the Strengbach creek flow during 


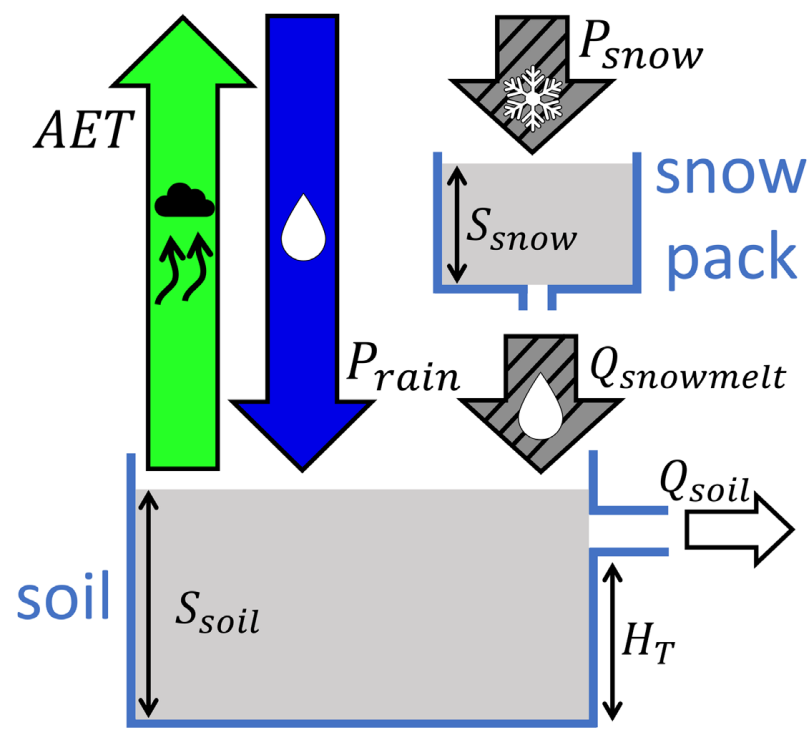

Figure 8. Working principle of the tank model. Modified from Jacob et al. (2010). The green arrow with the cloud represents the actual evapotranspiration AET, the grey arrow with the snowflake represents the snow fall $P_{\text {snow }}$, the blue arrow with the droplet represents the rain fall $P_{\text {rain }}$, the grey arrow with the streamline represents the melt water infiltrating the subsurface $Q_{\text {snowmelt }}$, and the white arrow represents the drainage of the subsurface compartment $Q_{\text {soil }}$.

and after winter peak flow events. This hypothesis is investigated in the next section.

\subsection{Tank model}

In this section, we aim to compare the drainage term representative of the SG footprint area and the Strengbach streamflow. In particular, we want to test whether the SG drainage term is effectively lower than the Strengbach streamflow during winter flood events. For this purpose, we adjusted a tank model (Fig. 8) run at a daily time step on the $\mathrm{SG}$ gravity signal (in $\mathrm{nm} \mathrm{s}^{-2}$ ). We follow the conceptual framework proposed by Jacob et al. (2010) and applied by Deville et al. (2013). The tank model represents the water circulation in the subsurface compartment referred as 'soil' (Fig. 8). Water input corresponds to the liquid rain $P_{\text {rain }}$ and snowmelt water $Q_{\text {snowmelt }}$. Water output corresponds to the actual evapotranspiration $A E T$ and to the subsurface drainage $Q_{\text {saprolite, }}$ which is governed by a linear discharge law with an infiltration threshold $H_{T}$ and a characteristic timescale $T$ (eq. 2 from Deville et al. 2013).

The total water storage is scaled on the SG gravity signal using a dimensionless factor $\mathrm{C}$ (eq. 7). For a comprehensive description of the adjustment of tank models on gravity signal, we refer to Deville et al. (2013).

$g_{\text {tank }}=2 \pi G \rho_{w} C\left(S_{\text {soil }}+S_{\text {snow }}\right)$

$g_{\text {tank }}$ (see eq. 6) is fitted to the SG local hydrological residual signal with a stochastic inversion by performing 100000 simulations with a uniform random sampling within parameter space (i.e. tank model parameters and initial water level). Accepted models correspond to a model having an RMSE smaller than 1.10 times the best model RMSE (Deville et al. 2013). The average and the standard deviation of the accepted model parameters are computed to determine the final tank parameter sets and their uncertainties.
The tank model scale factor $C$ is $0.87 \pm 0.10$, which is equivalent to an admittance factor of $0.36 \pm 0.04 \mathrm{~nm} \mathrm{~s}^{-2} \mathrm{~mm} \mathrm{Water}^{-1}$. The tankmodel admittance is not significantly different from the rainfall admittance value we found $\left(0.45 \pm 0.08 \mathrm{~nm} \mathrm{~s}^{-2} \mathrm{~mm} \mathrm{Water}^{-1}\right.$, see Section 3.2). The tank model characteristic discharge time $T$ is $55 \pm 10 \mathrm{~d}$ and threshold $H_{T}$ is $65 \pm 15 \mathrm{~mm}$. This threshold value is of the same magnitude than values ranging from 21 to $82 \mathrm{~mm}$ water found by adjusting the same model on AG measurements performed in a rather different karstic context (Deville et al. 2013). In this study, the value we found for $H_{T}$ is not negligible compared to the range of $\mathrm{SG}_{\mathrm{WSC}}$ (it represents 26 per cent of $\mathrm{SG}_{\mathrm{WSC}}^{\mathrm{Max}}$ range and as much as 44 per cent of $\mathrm{SG}_{\mathrm{WSC}}^{\mathrm{Min}}$ ). It suggests that a significant part of subsurface water storage is not available for drainage, possibly because it is mobilized by the vegetation for evapotranspiration, as identified by Rempe (2016).

The tank model properly reproduces seasonal variations of the SG signal (Fig. 9a), and it is significantly closer to the SG signal than the CWB (RMSE of $11 \mathrm{~nm} \mathrm{~s}^{-2}$ for the best single-tank model compared to an RMSE of $33 \mathrm{~nm} \mathrm{~s}^{-2}$, respectively $40 \mathrm{~nm} \mathrm{~s}^{-2}$ between CWB and $\mathrm{SG}_{\mathrm{WSC}}^{\mathrm{Min}}$ or $\mathrm{SG}_{\mathrm{WSC}}^{\mathrm{Max}}$, see Table 2). In particular, both 2018 and 2019 June to July gravity recession curves are remarkably well reproduced by the single-tank model. But more importantly, the tank model gravity signal does not significantly differ from the SG signal during and after the 2019 March flood event, as the SG signal is comprised within the grey area covered by acceptable tank models (Fig. 9a). The misfit between the SG signal and the tank model gravity is larger during the period following the 2018 January flood events. In particular, from the 2018 January 18 to the February 16, the SG signal is outside from the acceptable tank models area. After the 2018 February 16, this offset vanished and both SG signal and tank model gravity do not significantly deviate anymore.

Both CWB and tank models have the same water input (effective precipitation, i.e. daily precipitation reduced from actual evapotranspiration, see Fig. 8) but differ in the water output: for CWB, the water output corresponds to the Strengbach streamflow, while the single tank water output is governed by a linear discharge law whose parameters are adjusted on the SG signal. Therefore, the better fit of the single-tank model (adjusted on the SG signal) compared to CWB can be fully attributed to the water drainage term. The Strengbach streamflow reached $25 \mathrm{~mm} \mathrm{~d}^{-1}$ for the 2018 January 23 snowmelt event and $16 \mathrm{~mm} \mathrm{~d}^{-1}$ for the 2019 March 16 event, while SG drainage reached respectively 5 and $3.5 \mathrm{~mm} \mathrm{~d}^{-1}$ (Fig. 9b). So, it confirms that during and after winter peak flow event, the drainage term in the surrounding of the SG is much lower than the Strengbach catchment streamflow. As a consequence, more water is evacuated at the catchment scale than in the SG footprint area which explains the long-lasting discrepancies between $\mathrm{SG}_{\mathrm{WSC}}$ and CWB that occur after winter flood events (see S 4.1). Interestingly, one can also note that the SG drainage is similar to the Strengbach catchment baseflow (Fig. 9b).

\subsection{Discussion}

We show that during winter peak flow events, the drainage term representative of the SG footprint area is significantly smaller than at the catchment scale. We argue that the SG signal is mostly representative of the upper part of the hydro-system, so that our results suggest that the lower part of the catchment is the major contributor to generation of peak flow of the Strengbach stream occurring during the wet period, that is, when the catchment storage is filled. This is in agreement with hydrologic and geochemical studies showing 

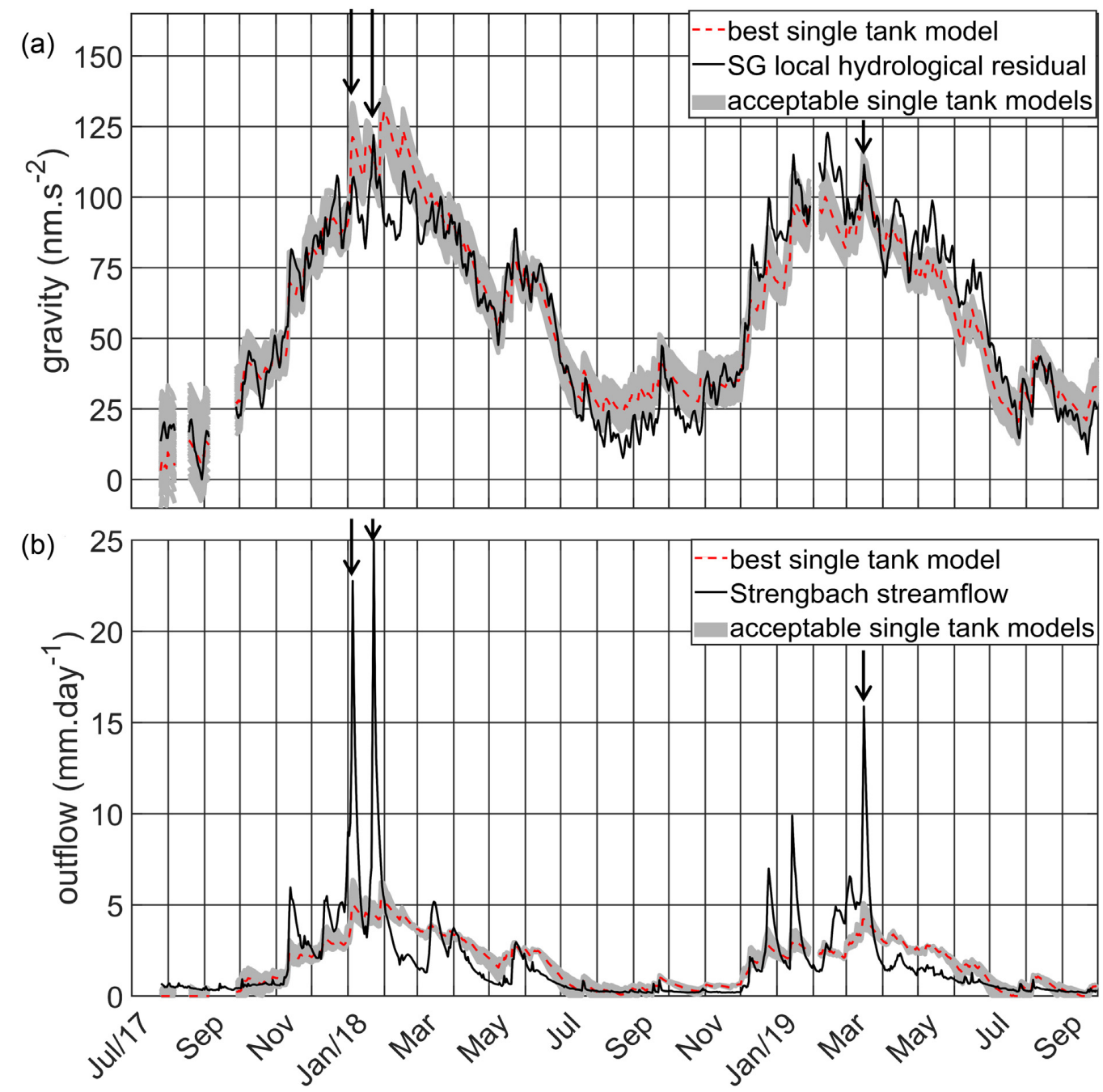

Figure 9. (a) Comparison between SG gravity (black line) and single-tank gravity signal (best single-tank model in dashed red, acceptable models in grey). (b) Comparison between Strengbach streamflow (black line) and single-tank model discharge (best single-tank model in dashed red, acceptable models in grey). Arrows indicate the 2018 January and 2019 March snowmelt events.

that the lower areas are hydrologically very reactive and have greater contributions during high water periods (Idir et al. 1999; Ladouche et al. 2001; Pierret et al. 2014).

Interestingly, our results are in agreement with other studies combining SG monitoring with streamflow measurements to get insight into the internal water storage dynamics of catchments: Fores et al. (2017) could properly reproduce the baseflow of the Durzon karstic catchment using a tank model adjusted on SG data, while they could not reproduce the Durzon peak-flows associated with highprecipitation events. They concluded that their SG station was located on a part of the catchment with high storage capacity and no significant fast transfer. In a context similar to the Strengbach catchment, Creutzfeldt et al. (2014) found a strong linear correlation between the monthly drainage term inferred from SG data and the baseflow of neighbouring headwater catchments, but they could not reproduce the strong peak flow events occurring at a daily timescale as those we discussed in this paper (see their fig. 5).

The deviation between the Strengbach streamflow and SG drainage may result from different causes: (i) due to its summit position the snowpack could remain longer around the SG than at the catchment scale, as a result of the large altitude difference between the outlet and the SG station (254 m). Such differential snowpack melting between the upper and the lower part of the catchment could explain why the SG drainage is lower than Strengbach streamflow during winter peak flow events. However, the hypothesis (i) can be disregarded for the events discussed in this study. Indeed, the melting of the pre-existing snowpack only contributed in a minor way to the generation of peak flow because pre-events snowpacks were small (Table 1). (ii) The SG drainage vs Strengbach streamflow discrepancies could also result from an extended pre-event water storage capacity in the upper part of the catchment compared to the lower part. Indeed, the water storage capacity of the lower part is likely already saturated before the onset of the precipitation events (that lead to the peak flows) so that it could directly contribute to the generation of peak flow, while the contribution of the upper part would be smoother and delayed because it is not water saturated and hence cannot contribute as much and as fast. Hypothesis (ii) is plausible as such mechanism was already identified by Rempe (2016) at the hillslope scale to explain the peak flow generation processes resulting from storm events. In this last study, author showed that gradient in the extent of the weathering zone between the crest and the valley bottom led to differences in the threshold precipitation needed to generate a groundwater response, which led to the lower portion of the hillslope contributing to storm runoff well before the 
upper part. However, hypothesis (ii) would require validation by assessing the water saturation state of the lower part of the catchment by implementing continuous hydrological monitoring with, for example, time-domain reflectometry probes or electrical resistivity tomography (Vereecken et al. 2014).

In this study, we discussed the SG drainage-Strengbach streamflow discrepancies in term of difference in water storage dynamics between the upper and the lower part of the Strengbach catchment, considering that the SG is representative of the upper part of the catchment. However, the SG signal also integrate the WSC occurring in the upper part of the neighboring Bourgade and Saint-PierreSur-l'Hâte catchments (Fig. 1). So that the SG drainage-Strengbach streamflow discrepancies could result from hydrological dynamics in the Bourgade and Saint-Pierre-Sur l'Hâte catchment that differ from the Strengbach catchment one. However, because the three catchments have similar topography, lithology, land cover and climate forcing (evapotranspiration and precipitation are measured at the summit weather station which is at the crossing point between the catchments), we argue that the Strengbach, Bourgade and SaintPierre-Sur-l'Hâte catchments should have a similar water balance. One could check this hypothesis by installing gauging stations on the creeks draining the Bourgade and Saint-Pierre-Sur-l'Hâte catchment.

\section{CONCLUSION}

We assessed water storage changes from in situ superconducting gravimetry monitoring $\left(\mathrm{SG}_{\mathrm{WSC}}\right)$ performed at the summit of the Strengbach mountain headwater catchment (Vosges mountains, France). We then compared $\mathrm{SG}_{\mathrm{WSC}}$ with the $\mathrm{CWB}$, showing that both exhibit strong similarities in terms of temporal pattern and amplitude, although they deviate significantly during the months following large winter peak flow events. We show that during and after such events, the drainage term representative of the SG footprint area is significantly smaller than at the catchment scale, which can explain the discrepancies between $\mathrm{CWB}$ and $\mathrm{SG}_{\mathrm{WSC}}$. We attributed this feature to a larger contribution of the lower part of the catchment to the generation of peak flows, compared to the upper part. During wet periods, the storage of the lower part of the catchment is likely water saturated, and is therefore very responsive to precipitation events, which lead to a rapid and large contribution to peak flow while the response of the upper part is smoother and delayed because of an extended water storage capacity compared to the saturated lower part of the catchment. Our study therefore illustrates the use of continuous terrestrial gravity monitoring to assess the water storage dynamics in a mountainous context (at the headwater Strengbach catchment in the Vosges mountains, France). It also shows that the topography significantly amplifies the sensitivity of the gravimeter to the water storage dynamics. Hence, this new gravimetric observatory could help to tackle exciting challenges of the $\mathrm{CZ}$ sciences such as the measurement of forest evapotranspiration.

\section{F UNDIN G}

The installation of iGrav\#30 superconducting gravimeter has been funded by Equipex CRITEX (https://www.critex.fr). The doctoral school ED413 from the Strasbourg university, as well as ANR HYDROCRIZSTO ANR-15-CE01-0010-02 funded Quentin Chaffaut's Ph.D. The OZCAR network (http://ozcar-ri.prod.lamp.cnrs. $\mathrm{fr} /$ ) also provided fundings for this study.

\section{AUTHORSHIP CONTRIBUTION STATEMEN T}

Quentin Chaffaut: Conceptualization, Methodology, Data acquisition, Data processing, Results analysis, Writing - original draft, Writing-review \& editing. Jacques Hinderer: Conceptualization, Methodology, Data curation, Writing - review \& editing, Funding acquisition, Supervision. Frédéric Masson: Conceptualization, Methodology, Writing — review \& editing, Supervision. Daniel Viville: Data acquisition, Data curation, Data processing, Supervision. Sylvain Pasquet: Data acquisition, Data curation, Data processing, Writing - review \& editing. Jean-Paul Boy: Data curation, Data processing. Jean-Daniel Bernard: Data acquisition, Data curation, Data processing. Nolwenn Lesparre: Data acquisition, Writing - review \& editing. Marie-Claire Pierret: Writingreview \& editing, Funding acquisition.

\section{ACKNOWLEDGEMENTS}

We thank OHGE (http://ohge.unistra.fr/) for providing all hydrometeorological data used in this study. We thank F. Rembert for helping us to acquire seismic profiles. We are very grateful for the considerable work done by the editor Duncan Agnew and two anonymous reviewers which greatly improved the quality of this paper.

\section{DATA AVAILABILITY}

Surface loading computation of GLDAS2 and MERRA2 hydrological loading as well as ECMWF atmospheric loading are available through the EOST loading service (http://loading.u-strasbg.fr). Polar motion is provided by the International Earth Rotation Service (ftp://hpiers.obspm.fr/ers/eop/eopc04/). iGrav\#30 gravity data, absolute gravity data and hydrometeorological data are available on request to the corresponding author.

\section{CONFLICT OF INTEREST}

The authors declare that they have no known competing financial interests or personal relationships that could have appeared to influence the work reported in this paper. Please note: Oxford University Press is not responsible for the content or functionality of any supporting materials supplied by the authors. Any queries (other than missing material) should be directed to the corresponding author for the paper.

\section{REFER E N CES}

Ambroise, B., 1995. Topography and the water cycle in a temperate middle mountain environment: the need for interdisciplinary experiments, Agr. Forest. Meteorol., 73, 217-235.

Arnoux, M., Halloran, L.J.S., Berdat, E. \& Hunkeler, D., 2020. Characterizing seasonal groundwater storage in alpine catchments using time-lapse gravimetry, water stable isotopes and water balance methods, Hydrol. Process., 1-15, doi:10.1002/hyp.13884.

Bogena, H.R, Huisman, J.A, Güntner, A., Hübner, C., Kusche, J., Jonard, F., Vey, S. \& Vereecken, H., 2015. Emerging methods for noninvasive sensing of soil moisture dynamics from field to catchment scale: a review, WIRES Water, 2, 635-647.

Boy, J.P., Gegout, P. \& Hinderer, J., 2002. Reduction of surface gravity data from global atmospheric pressure loading, Geophys. J. Int., 149, 534-545.

Boy, J.P. \& Hinderer, J., 2006. Study of the seasonal gravity signal in superconducting gravimeter data, J. Geodyn., 41, 227-233. 
Brooks, P.D., Chorover, J., Fan, Y., Godsey, S.E., Maxwell, R.M., McNamara, J.P. \& Tague, C., 2015. Hydrological partitioning in the critical zone: recent advances and opportunities for developing transferable understanding of water cycle dynamics, Water Resour. Res., 51, 6973-6987.

Calvo, M., Hinderer, J., Rosat, S., Legros, H., Boy, J.P., Ducarme, B. \& Zürn, W., 2014. Time stability of spring and superconducting gravimeters through the analysis of very long gravity records, J. Geodyn., 80, 20-33.

Chaffaut, Q., Hinderer, J., Masson, F., Viville, D., Bernard, J.D., Cotel, S., Pierret, M.C., Lesparre, N. et al., 2020. Continuous monitoring with a superconducting gravimeter as a proxy for water storage changes in a mountain catchment, International Association of Geodesy Symposia. Springer, Berlin, Heidelberg, doi:10.1007/1345_2020_105.

Christiansen, L., Binnning, P.J., Rosbjerg, D., Andersen, O.B. \& BauerGottwein, P., 2011. Using time-lapse gravity for groundwater model calibration: an application to alluvial aquifer storage, Water Resour. Res., 47, doi:10.1029/2010WR009859.

Creutzfeldt, B., Ferré, T., Troch, P., Merz, B., Wziontek, H. \& Güntner, A., 2012. Total water storage dynamics in response to climate variability and extremes: inference from long-term terrestrial gravity measurement, $J$. geophys. Res.: Atmospheres, 117, doi:10.1029/2011JD016472.

Creutzfeldt, B., Güntner, A., Klügel, T. \& Wziontek, H., 2008. Simulating the influence of water storage changes on the superconducting gravimeter of the Geodetic Observatory Wettzell, Germany, Geophysics, 73(6), doi:10.1190/1.2992508.

Creutzfeldt, B., Güntner, A., Thoss, H., Merz, B. \& Wziontek, H., 2010b. Measuring the effect of local water storage changes on in-situ gravity observations: case study of the Geodetic Observatory Wettzell, Germany, Water Resour. Res., 46, W08531, doi:10.1029/2009WR008359.

Creutzfeldt, B., Güntner, A., Wziontek, H. \& Merz, B., 2010a. Reducing local hydrology from high precision gravity measurements: a lysimeterbased approach, Geophys. J. Int., 183, 178-187.

Creutzfeldt, B., Troch, P., Güntner, A., Ferré, T., Graeff, T. \& Merz, B., 2013. Storage-discharge relationships at different catchment scales based on local high-precision gravimetry, Hydrol. Process., doi:10.1002/hyp.9689.

Delobbe, L., Watlet, A., Wilfert, S. \& Van Camp, M., 2019. Exploring the use of underground gravity monitoring to evaluate radar estimates of heavy rainfall, Hydrol. Earth Syst. Sci., 23, 93-105.

Deville, S., Jacob, T., Chéry, J. \& Champollion, C., 2013. On the impact of topography and building mask on time varying gravity due to local hydrology, Geophys. J. Int., 192(1), 82-93.

El Gh'Mari, 1995. Etude Minéralogique, Pétrophysique et Géochimique de la Dynamique d'altération d'un Granite Soumis aux Dépots Atmosphériques Acides (bassin versant du Strengbach, Vosges, France): Mécanismes, Bilans et Modélisations. PhD dissertation Strasbourg 1 Univ., Strasbourg, France.

Flinchum, B.A., et al., 2018. Critical zone structure under a granite ridge inferred from drilling and three-dimensional seismic refraction data, $J$. geophys. Res.: Earth Surface, 123(6), 1317-1343.

Flury, J., Peters, T., Schmeer, M., Timmen, L., Wilmes, H. \& Falk, R., 2007. Precision gravimetry in the new Zugspitze gravity meter calibration system, Harita Dergisi, 18, 401-406.

Fores, B., Champollion, C., Le Moigne, N., Bayer, R. \& Chéry, J., 2017. Assessing the precision of the iGrav superconducting gravimeter for hydrological models and karstic hydrological process identification, Geophys. J. Int., 208(1), 269-280.

Fores, B., Champollion, C., Mainsant, G., Albaric, J. \& Fort, A., 2018. Monitoring saturation changes with ambient seismic noise and gravimetry in a karst environment, Vadose Zone J., 17(1), 1-12.

Fores, B., Klein, G., Le Moigne, N. \& Francis, O., 2019. Long-Term stability of Tilt-Controlled gPhoneX gravimeters, J. geophys. Res.: Solid Earth, 124(11), doi:10.2136/vzj2017.09.0163.

Gaillardet, J., et al., 2018. OZCAR: the French network of critical zone observatories, Vadose Zone J., 17, 180067, doi:10.2136/vzj2018.04.0067.

Gelaro, R., et al., 2017. The Modern-Era retrospective analysis for research and applications, version 2 (MERRA-2), J. Climate, 30, doi:10.1175/JCLI-D-16-0758.1.
Granier, A., Bréda, N., Biron, P. \& Villette, S., 1999. A lumped water balance model to evaluate duration and intensity of drought constraints in forest stands, Ecol. Model, 116, doi:10.1016/S0304-3800(98)00205-1.

Grant, G.E., Tague, C.L. \& Allen, C.D., 2013. Watering the forest for the trees: an emerging priority for managing water in forest landscapes, Front. Ecol. Environ., 11(6), 314-321.

Greene, C.A., Thirumalai, K., Kearney, K.A.,Delgado, J.M.,Schwanghart, W.\& Wolfenbarger, N.S., 2019. The climate data toolbox for MATLAB. Geochem. Geophys. Geosyst., doi:10.1029/2019GC008392.

Güntner, A., Reich, M., Mikolaj, M., Creutzfeldt, B., Schroeder, S. \& Wziontek, H., 2017. Landscape-scale water balance monitoring with an iGrav superconducting gravimeter in a field enclosure, Hydrol. Earth Syst. Sci., 21, 3167-3182.

Hasan, S., Troch, P.A., Bogaart, P.W. \& Kroner, C., 2008. Evaluating catchment-scale hydrological modeling by means of terrestrial gravity observations, Water Resour. Res., 44, W08416, doi:10.1029/2007WR006321.

Hector, B., Cohard, J.M., Séguis, L., Galle, S. \& Peugeot, C., 2018. Hydrological functioning of western African inland valleys explored with a critical zone model, Hydrol. Earth Syst. Sci, 22, 5867-5888.

Hector, B., Hinderer J.,Séguis, L., Boy J.P., Calvo M., Descloitres M., Rosat S., Galle S.\& Riccardi U., 2014. Hydro-gravimetry in West-Africa: first results from the Djougou (Benin) superconducting gravimeter, J. Geodyn., 80, doi:10.1016/j.jog.2014.04.003.

Henrion, E., Masson, F., Doubre, C., Ulrich, P. \& Meghraoui, M., 2020. Present-day deformation in the Upper Rhine Graben from GNSS data, Geophys. J. Int., 223, 599-611.

Hinderer, J., Crossley, D. \& Warburton, R.J., 2015. Superconducting Gravimetry. In: Gerald Schubert (editor-in-chief) Treatise on Geophysics, 2nd edn, vol. 3. Oxford: Elsevier, pp. 59-115.

Hinderer, J., Hector, B., Riccardi, U., Rosat, S., Boy, J.P., Calvo, M., Little, F. \& Bernard, J.D., 2020. A study of the monsoonal hydrology contribution using a 8-yr record (2010-2018) from superconducting gravimeter OSG060 at Djougou (Benin, West Africa), Geophys. J. Int., 221, 431-439.

Holbrook, W.S., et al. 2014. Geophysical constraints on deep weathering and water storage potential in the Southern Sierra Critical Zone Observatory, Earth Surf. Process. Landforms, 39, 366-380.

Holbrook, W.S., Marcon, V., Bacon, A.R., Brantley, S.L., Carr, B.J., Flinchum, B.A., Richter, D.D. \& Riebe, C.S., 2019. Links between physi$\mathrm{cal}$ and chemical weathering inferred from a 65 -m-deep borehole through Earth's critical zone, Sci. Rep. UK, 9. doi:10.1038/s41598-019-40819-9.

Idir, S., Probst, A., Viville, D. \& Probst, J.L., 1999. Contribution of saturated areas and billslopes to the watter and element fluxes exported during a storm event: tracing with dissolved organic carbon and silica. The Strengbach catchment case study (Vosges, France), Compt. Rend. Acad. Sci. Ser. IIA Earth Planet. Sci., 2(328), 89-96.

Imanishi, Y., Kokubo, K. \& Tatehata, H., 2006. Effect of underground water on gravity observation at Matsushiro, Japan, J. Geodyn., 41, 221-226.

Jacob, T., Bayer, R., Chery, J. \& Le Moigne, N., 2010. Time-lapse microgravity surveys reveal water storage heterogeneity of a karst aquifer, $J$. geophys. Res., 115, B06402, doi:10.1029/2009JB006616.

Jacob, T., et al., 2008. Absolute gravity monitoring of water storage variation in a karst aquifer on the larzac plateau (Southern France), J. Hydrol., 359, $105-117$.

Kroner, C. \& Jahr, Th., 2006. Hydrological experiments around the superconducting gravimeter at Moxa Observatory, J. Geodyn., 41, 268-275.

Ladouche, B., Probst, A., Viville, D., Idir, S., Baque, D., Loubet, M., Probst, J.-L. \& Bariac, T., 2001. Hydrograph separation using isotopic, chemical and hydrological approaches (Strengbach catchment, France), J. Hydrol., 242, 255-274.

Leirião, S., He, X., Christiansen, L., Andersen, O.B. \& Bauer-Gottwein, P., 2009. Calculation of the temporal gravity variation from spatially variable water storage change in soils and aquifers, J. Hydrol., 365, doi:10.1016/j.jhydrol.2008.11.040.

Lesparre, N., et al. 2020. Magnetic resonance sounding measurements as posterior information to condition hydrological model parameters: application to a hard-rock headwater catchment, J. Hydrol., 124941, doi:10.1016/j.jhydrol.2020.124941. 
Llubes, M., Florsch, N., Hinderer, J., Longuevergne, L. \& Amalvict, M., 2004. Local hydrology, the Global Geodynamics Project and CHAMP/GRACE perspective: some case studies, J. Geodyn., 38, 355374.

Longuevergne, L., Boy, J.P., Florsch, N., Viville, D., Ferhat, G., Ulrich, P., Bernard, L. \& Hinderer, J., 2009. Local and global hydrological contributions to gravity variations observed in Strasbourg, J. Geodyn., 48, 189-194.

Lyard, F., Lefevre, F., Letellier, T. \& Francis, O., 2006. Modelling the global ocean tides: modern insights from FES2004. Ocean Dyn., 56, 394-415.

Masson, F., Viville, D., Pierret, M-C., Mouyen, M., Hecker, L. \& Chabaux, F., 2012. Time-lapse microgravity study of the Strengbach catchment (Vosges mountains, France). Cr. Geosci., 344, 357-365.

Meurers, B., Van Camp, M. \& Petermans, T., 2007. Correcting superconducting gravity time-series using rainfall modelling at the Vienna and Membach stations and application to Earth tide analysis, J. Geod., 81, 703-712.

Mikolaj, M., et al., 2019. Hydrometeorological and gravity signals at the Argentine-German Geodetic Observatory (AGGO) in La Plata, Earth Syst. Sci. Data Disc., 11, 1501-1513.

Mikolaj, M., Meurers, B. \& Mojzes, M., 2015. The reduction of hydrologyinduced gravity variations at sites with insufficient hydrological instrumentation, Stud. Geophys. Geod., 59(2015), 424-437.

Mouyen, M., Masson, F., Hwang, C., Cheng, C.C, Le Moigne, N., Lee, C.W., Kao, R. \& Hsieh, W.C., 2012. Erosion effects assessed by repeated gravity measurements in southern Taiwan, Geophys. J. Int., 192, 113-136.

Naujoks, M., Kroner, C., Weise, A., Jahr, T., Krause, P. \& Eisner, S., 2010. Evaluating local hydrological modelling by temporal gravity observations and a gravimetric three-dimensional model: gravity and hydrology: local 3-D modelling, Geophys. J. Int. doi:10.1111/j.1365-246X.2010.04615.x.

Parsekian, A.D., Singha, K., Minsley, B.J., Holbrook, W.S. \& Slater, L., 2015. Multiscale geophysical imaging of the critical zone, Rev. Geophys., 53, 1-26.

Pfeffer, J., et al., 2011. Local and global hydrological contributions to timevariable gravity in Southwest Niger: hydrology and gravity in SW Niger, Geophys. J. Int., 184, 661-672.

Pfeffer, J., et al., 2013. Evaluating surface and subsurface water storage variations at small time and space scales from relative gravity measurements in semiarid Niger. Water Resour. Res., 49, 3276-3291.

Pierret, M.C., et al., 2018. The Strengbach Catchment: a multidisciplinary environmental sentry for 30 years, Vadose Zone J., 17, 180090, doi:10.2136/vzj2018.04.0090.

Pierret, M.C., Stille, P., Prunier, J., Viville, D. \& Chabaux, F.(2014). Chemical and U-Sr isotopic variations in stream and source waters of the Strengbach watershed (Vosges mountains, France). Hydrol. Earth Syst. Sci., 18(10), 3969-3985.

Reich, M., Mikolaj, M., Blume, T. \& Güntner, A., 2019. Reducing gravity gravity data for the influence of water storage variations beneath observatory buildings, Geophysics, 84(1), 15-31.

Rempe, D.M., 2016. Controls on Critical Zone Thickness and Hydrologic Dynamics at the Hillslope Scale, PhD dissertation, 215pp, Earth and Planet. Sci., Univ. of Calif., Berkeley.

Rodell, M., et al., 2004. The global land data assimilation system, Bull. Amer. Meteor. Soc., 85(3), 381-394

Rosat, S., et al., 2018. A two-year analysis of the iOSG-24 superconducting gravimeter at the low noise underground laboratory (LSBB URL) of Rustrel, France: environmental noise estimate, J. Geodyn., 119, doi:10.1016/j.jog.2018.05.009.

Van Camp, M., de Viron, O., Pajot-Métivier, G., Casenave, F., Watlet, A., Dassargues, A. \& Vanclooster, M., 2016. Direct measurement of evapotranspiration from a forest using a superconducting gravimeter, Geophys. Res. Lett., 43, 10,225-210,231.
Van Camp, M., Vanclooster, M., Crommen, O., Petermans, T., Verbeeck, K., Meurers, B., van Dam, T. \& Dassargues, A., 2006. Hydrogeological investigations at the Membach station, Belgium, and application to correct long periodic gravity variations, J. geophys. Res., 111, B10403, doi:10.1029/2006JB004405.

Vereecken, H., et al., 2014. On the spatio-temporal dynamics of soil moisture at the field scale, J. Hydrol., 516(2014), 76-96.

Viviroli, D., Dürr, H.H., Messerli, B., Meybeck, M. \& Weingartner, R., 2007. Mountains of the world, water towers for humanity: typology, mapping, and global significance, Water Resour. Res., 43, W07447, doi:10.1029/2006WR005653.

Viviroli, D., et al., 2011. Climate change and mountain water resources: overview and recommendations for research, management and policy, Hydrol. Earth Syst. Sci., 15, 471-504.

Voigt, C., et al., 2021. Introduction of a superconducting gravimeter as novel hydrological sensor for the alpine research catchment zugspitze, Hydrol. Earth Syst. Sci. Discuss. [preprint], doi:10.5194/hess-2021-78, in review.

Warburton, R.J., Pillai, H. \& Reineman, R.C., 2010. Initial results with the new GWR iGrav ${ }^{\mathrm{TM}}$ superconducting gravity meter. Published in International Association of Geodesy (IAG) Symposium Proceedings. IAG Symposium on Terrestrial Gravimetry: Static and Mobile Measurements (TG-SMM2010) 22 - 25 June 2010, Russia, Saint Petersburg.

Watlet, A., Van Camp, M., Francis, O., Poulain, A., Rochez, G., Hallet, V., Quinif, Y. \& Kaufmann, O., 2020. Gravity monitoring of underground flash flood events to study their impact on groundwater recharge and the distribution of karst voids, Water Resour. Res., 56, e2019WR026673, doi:10.1029/2019WR026673.

Weill, S., Delay, F., Pan, Y. \& Ackerer, P., 2017. A low-dimensional subsurface model for saturated and unsaturated flow processes: ability to address heterogeneity, Comput. Geosci., 21. doi:10.1007/s10596-017-9613-8.

Weill, S., Lesparre, N., Jeannot, B. \& Delay, F., 2019. Variability of water transit time distributions at the Strengbach catchment (Vosges Mountains, France) inferred through integrated hydrological modeling and particle tracking algorithms, Water, 11(12), 2637. doi:10.3390/w11122637.

\section{SUPPORTING INFORMATION}

Supplementary data are available at $G J I$ online.

Figure S1. Data and model used to compute the snow water equivalent. (a) Algorithm used to compute the daily meltwater flux $Q_{\text {snowmelt }}, i-1$ and $i$ refer to time indices, $S_{\text {snow }}$ refers to the snow water equivalent, $\Delta h_{\text {snow }}$ refers to the snow height difference between time $i$ and time $i-1$ (it is negative if the snow height decreased between time $i-1$ and time $i$ ). (b) Snow gauge used to measure the snow height at the summit weather station.

Figure S2. Structure of the Strengbach precipitation field measured at a height of $0.3 \mathrm{~m}$.

Figure S3. Underground seismic velocity nearby SG station inferred from seismic tomography. For better visualization, white isodepth lines are drawn at depth of 5, 10 and $15 \mathrm{~m}$.

Figure S4. Topographic admittance map. Altitude difference between iso-level lines is $10 \mathrm{~m}$

Please note: Oxford University Press is not responsible for the content or functionality of any supporting materials supplied by the authors. Any queries (other than missing material) should be directed to the corresponding author for the paper. 